\title{
Molecular Mechanism of Constitutive Endocytosis of Acid-Sensing Ion Channel 1a and Its Protective Function in Acidosis-Induced Neuronal Death
}

\author{
Wei-Zheng Zeng, ${ }^{1,2}$ Di-Shi Liu, ${ }^{2}$ Bo Duan, ${ }^{1}$ Xing-Lei Song, ${ }^{2}$ Xiang Wang, ${ }^{2}$ Dong Wei, ${ }^{3}$ Wen Jiang, ${ }^{3}$ Michael X. Zhu, ${ }^{4}$ \\ Yong $\mathrm{Li}^{2}{ }^{2}$ and Tian-Le $\mathrm{Xu}^{2}$ \\ ${ }^{1}$ Institute of Neuroscience and State Key Laboratory of Neuroscience, Shanghai Institutes for Biological Sciences, Chinese Academy of Sciences, Shanghai \\ 200031, China, ${ }^{2}$ Department of Anatomy and Embryology, Department of Biochemistry and Molecular Cell Biology and Shanghai Key Laboratory for \\ Tumor Microenvironment and Inflammation, Institute of Medical Sciences, Shanghai Jiao Tong University School of Medicine, Shanghai 200025, China, \\ ${ }^{3}$ Department of Neurology, Xijing Hospital, the Fourth Military Medical University, Xi'an 710032, China, and ${ }^{4}$ Department of Integrative Biology and \\ Pharmacology, University of Texas Health Science Center at Houston, Houston, Texas 77030
}

Acid-sensing ion channels (ASICs) are proton-gated cation channels widely expressed in the peripheral and CNSs, which critically contribute to a variety of pathophysiological conditions that involve tissue acidosis, such as ischemic stroke and epileptic seizures. However, the trafficking mechanisms of ASICs and the related proteins remain largely unknown. Here, we demonstrate that ASIC1a, the main ASIC subunit in the brain, undergoes constitutive endocytosis in a clathrin- and dynamin-dependent manner in both mouse cortical neurons and heterologous cell cultures. The endocytosis of ASIC1a was inhibited by either the small molecular inhibitor tyrphostin A23 or knockdown of the core subunit of adaptor protein 2 (AP2) $\mu 2$ using RNA interference, supporting a clathrin-dependent endocytosis of ASIC1a. In addition, the internalization of ASIC1a was blocked by dominant-negative dynamin 1 mutation K44A and the small molecular inhibitor dynasore, suggesting that it is also dynamin-dependent. We show that the membrane-proximal residues ${ }^{465} \mathrm{LCRRG}^{469}$ at the cytoplasmic C terminus of ASIC1a are critical for interaction with the endogenous adaptor protein complex and inhibition of ASIC1a internalization strongly exacerbated acidosis-induced death of cortical neurons from wild-type but not ASIC1a knock-out mice. Together, these results reveal the molecular mechanism of ASIC1a internalization and suggest the importance of endocytic pathway in functional regulation of ASIC1a channels as well as neuronal damages mediated by these channels during neurodegeneration.

\section{Introduction}

Acid-sensing ion channels (ASICs) are activated by extracellular protons and belong to the epithelial sodium channel/degenerin (ENaC/DEG) family. Among all seven ASIC subunits (1a, 1b, $1 \mathrm{~b} 2,2 \mathrm{a}, 2 \mathrm{~b}, 3$, and 4) identified, ASIC1a plays an essential role for determining proton-activated responses in the CNS (Xiong et al.,

Received Nov. 7, 2012; revised Feb. 22, 2013; accepted March 16, 2013.

Author contributions: W.-Z.Z., D.-S.L., B.D., M.X.Z., and T.-L.X. designed research; W.-Z.Z., D.-S.L., B.D., X.-L.S., X.W., and D.W. performed research; D.-S.L., W.J., and Y.L. contributed unpublished reagents/analytic tools; W.-Z.Z. and T.-L.X. analyzed data; W.-Z.Z., B.D., M.X.Z., and T.-L.X. wrote the paper.

This work was supported by the National Natural Science Foundation of China Grants 31230028, 91213306, and 91132303, National Institutes of Health Grants R01DK081654 and R01GM081658, Shanghai Municipal Education Commission (Leading Academic Discipline Project, J50201), and Shanghai Committee of Science and Technology (11DZ2260200). We thank all groups that provided us with ASIC CDNAs; Dr. M. J. Welsh (Howard Hughes Medical Institute, University of lowa, lowa City, lowa) for providing ASIC1 a knock-out mice; and Hui Cao, Jin Cheng, and Ying Li for their technical assistance.

The authors declare no competing financial interests.

Correspondence should be addressed to Dr. Tian-Le Xu, Department of Anatomy and Embryology, Department of Biochemistry and Molecular Cell Biology and Shanghai Key Laboratory for Tumor Microenvironment and Inflammation, Institute of Medical Sciences, Shanghai Jiao Tong University School of Medicine, Shanghai 200025, China. E-mail:xu-happiness@shsmu.edu.cn.

B. Duan's present address: Dana-Farber Cancer Institute and Department of Neurobiology, Harvard Medical School, 1 Jimmy Fund Way, Boston, MA 02115

DOI:10.1523/JNEUROSCI.5206-12.2013

Copyright $\odot 2013$ the authors $\quad 0270-6474 / 13 / 337066-13 \$ 15.00 / 0$
2008; Xu and Duan, 2009; Grunder and Chen, 2010). Under pathological conditions with tissue acidosis, ASIC1a contributes to axonal degeneration (Friese et al., 2007), neuronal death (Xiong et al., 2004; Gao et al., 2005; Duan et al., 2011), and chronic pain (Duan et al., 2007). Questions on how ASICs transport under normal and pathological conditions are currently the subject of active exploration. We recently demonstrated that BDNF facilitated the forward insertion of ASIC1a channels in spinal dorsal horn neurons and thereby contributed to pain hyperalgesia (Duan et al., 2012). However, despite intensive research, the molecular mechanism that controls ASICs endocytosis and its pathological relevance remains largely unknown.

Endocytosis plays a key role in cell surface expression for many receptors and ion channels. Defects in endocytosis cause dysfunctions of ion channels, ultimately leading to a variety of disorders (Piwon et al., 2000; Mankouri et al., 2006; Fang et al., 2009). Clathrin-mediated endocytosis is a process by which specific cargoes (such as ion channels) are internalized from the plasma membrane into clathrin-coated vesicles (Sorkin and von Zastrow, 2009). Adaptor protein 2 (AP2), the most-characterized clathrin adaptor, binds to the cytoplasmic domains of receptors and links membrane proteins to clathrin, promoting assembly of 
clathrin coats. This constitutes a key early step in endocytosis (McMahon and Boucrot, 2011). In ENaC channels, which have substantial homology to ASICs (Kellenberger and Schild, 2002), dysfunction of endocytosis primarily regulated by Nedd4-2, an E3 ubiquitin ligase, has been demonstrated in Liddle syndrome (Henry et al., 2003; Knight et al., 2006). In particular, mutations in the PY motifs (PPPXYXXL) located in the C terminus of $\beta$ - or $\gamma$-ENaC disrupted its association with Nedd4-2, leading to increased ENaC expression at the cell surface (Shimkets et al., 1994; Snyder et al., 1995; Schild et al., 1996). Interestingly, endocytic pathway dysfunctions have been found in various neurodegenerative disorders, such as Alzheimer's disease, lateral sclerosis, and ischemia (Nixon, 2005; Rudinskiy et al., 2009). In light of previous studies showing that clathrin adaptor AP2 complex regulates endocytosis of various ion channels, we hypothesized that ASICs may be regulated by clathrin-dependent endocytosis and dysfunction of ASIC endocytosis during ischemia may exacerbate acidosis-induced neuronal injury.

Here, we demonstrate that endocytosis of ASIC1a occurs through clathrin-mediated and dynamin-dependent processes in both mouse brain and heterologous cell cultures. Particularly, the membrane-proximal residues ${ }^{465}{ }^{2 C R R G}{ }^{469}$ at the $\mathrm{C}$ terminus of ASIC1a, representing a novel noncanonical sorting signal, is required for interaction with the endocytic complex. Furthermore, inhibition of ASIC1a internalization exacerbates acidosisinduced neuronal death. These results provide novel insights into the mechanisms of ASIC1a regulation and implicate that targeting the endocytic pathway of ASICs may help prevent neuronal injury during tissue acidosis, which is commonly associated with ischemia, epileptic seizure, and brain trauma.

\section{Materials and Methods}

Primary neuronal cultures and Chinese hamster ovary cell lines. All animal protocols were approved by the Institutional Animal Care and Use Committee of Institute of Neuroscience, Shanghai, China. Dissociated neurons were prepared and maintained as previously described (Duan et al., 2007). Briefly, cerebral cortices from 16-day-old embryonic SD rats or C57BL/6J wild-type (WT) and ASIC1a knock-out mice (KO, with congenic C57BL/6J background) were dissected and dissociated by $0.05 \%$ trypsin in D-Hank's solution for $10 \mathrm{~min}$. Cells were plated $\left(3-5 \times 10^{5}\right.$ cells/35 mm dish for electrophysiology and immunocytochemistry; 1.5$2 \times 10^{6}$ cells/ $60 \mathrm{~mm}$ dish for biochemistry) on poly-D-lysine (Sigma) coated cover glasses or dishes (Corning). Cultures were maintained in Neurobasal medium containing 2\% B27 and 1\% Glutamax supplements (Invitrogen) at $37^{\circ} \mathrm{C}$ for $7-16 \mathrm{~d}$ before experiments. Chinese hamster ovary (CHO) K1 cells were grown in F12K medium with 10\% FBS and $1 \%$ penicillin/streptomycin (Invitrogen). CHO cells stably expressing GFP-ASICla were maintained in the presence of G418 (200 $\mu \mathrm{g} / \mathrm{ml}$, A.G. Scientific).

Transfection and plasmids. CHO cells (at a density of 50-70\%) or cultured cortical neurons at DIV 7-8 were transfected with an appropriate amount of DNA ( $3.5 \mu \mathrm{g}$ DNA in $35 \mathrm{~mm}$ dishes for electrophysiology and immunocytochemistry; $8 \mu \mathrm{g}$ DNA in $60 \mathrm{~mm}$ dishes or $20 \mu \mathrm{g}$ DNA in $100 \mathrm{~mm}$ dishes for biochemistry) mixed with HilyMax liposome transfection reagent (Dojindo Laboratories) following the manufacturer's instruction. The amount of each plasmid for cotransfection was equal. Proteins were allowed to express for $1-3 \mathrm{~d}$ before experiments. The cDNA of human ASIC1a was cloned into the pEGFP-C3 vector (Clontech). For the HA-ASICla plasmid, the hemagglutinin (HA) epitope (YPYDVPDYA) of influenza virus was inserted in the extracellular loop of human ASICla between residues ${ }^{147} \mathrm{~F}$ and ${ }^{148} \mathrm{~K}$ (Chen and Grunder, 2007). For GFP-ASICla plasmid, GFP was linked at the N terminus of human ASIC1a. Mouse dynamin1 and human dynamin1 K44A cDNA constructs were kindly provided by Dr. Yong Li (Shanghai Jiao Tong University School of Medicine). For transfection, both dynamin1 and
K44A were cloned into the pEGFP-N1 vector (Clontech). Cytoplasmic domains of human ASIC1a, including amino acids 1-41 and 465-528, were cloned into the pGEX4T-1 vector (GE Biosciences) and resulted in an in-frame fusion with glutathione-S-transferase (GST). Mutations were generated by the QuikChange mutagenesis kit (Stratagene) following the manufacturer's instruction. All PCR-modified constructs were confirmed by DNA sequencing. AP2 $\mu 2$ short hairpin RNAs (shRNA) were cloned into pAKD-CMV-bGlobin-EGFP-H1-shRNA vector (Sunbio), where EGFP and shRNA expression were driven by the CMV and the H1 RNA polymerase III promoters, respectively. The efficiency of these shRNA constructs was tested in $\mathrm{CHO}$ cells overexpressing mCherry-AP $2 \mu 2$. The best one (shAP $2 \mu 2$, with the targeting sequence in mouse AP2 $\mu 2$ mRNA being 5' -CCATTGTATGGAAGATCAA-3') was used throughout the study. The control ( $\mathrm{Scr}$ ) contained a scrambled sequence (5'-GAGAATCGTAATTAGCATC-3'), which is without any detectable target among the mouse transcripts by BLAST search.

Biotinylated endocytosis assay. Cultured cortical neurons or $\mathrm{CHO}$ cells were washed three times with ice-cold PBS ${ }^{+/+}$solution $(\mathrm{PBS}+1 \mathrm{~mm}$ $\mathrm{MgCl}_{2}$ and $0.4 \mathrm{~mm} \mathrm{CaCl}_{2}, \mathrm{pH} 8.0$ ). To measure channel internalization, surface proteins were prelabeled with $0.25 \mathrm{mg} / \mathrm{ml}$ membraneimpermeable Sulfo-NHS-SS-biotin (Thermo Scientific) in PBS ${ }^{+/+}$solution on ice; there was little endocytosis when cells were incubated at $4^{\circ} \mathrm{C}$ or below. Unbound biotin group was quenched by $\mathrm{PBS}{ }^{+/+}$solution containing $0.1 \mathrm{~m}$ glycine. Cells were returned to the incubator at $37^{\circ} \mathrm{C}$ for various periods of time as indicated. At the end of each time point, cells were quickly chilled down to $4^{\circ} \mathrm{C}$. To evaluate the effects of tyrphostin A23 (Tyr A23; Santa Cruz Biotechnology) and dynasore (Tocris Bioscience) on endocytosis, drugs were added $30 \mathrm{~min}$ before biotinylation and presented during internalization at $37^{\circ} \mathrm{C}$. The surface biotin group was stripped off by the membrane-impermeable reducing agent MESNA (100 mM, Sigma) in TBS/C solution (50 mm Tris-HCl, pH 8.6, $100 \mathrm{~mm}$ $\mathrm{NaCl}$, and $2.5 \mathrm{~mm} \mathrm{CaCl}_{2}$ ) and quenched by $50 \mathrm{~mm}$ iodoacetamide (Sigma). Cells were lysed in $300 \mu \mathrm{l}$ of coimmunoprecipitation (co-IP) buffer (20 mm Tris-HCl, pH 8.0, $137 \mathrm{~mm} \mathrm{NaCl}, 10 \%$ glycerol, $1 \%$ Nonidet P-40, and 2 mm EDTA), including a Protease Inhibitor Mixture (Sigma). Cell lysates were sonicated briefly and centrifuged at $16,000 \times g$, $4^{\circ} \mathrm{C}$, for $15 \mathrm{~min}$. Ten percent volume of the lysate was separated as total (T) proteins and mixed with $4 \times$ Laemmli sample buffer (Bio-Rad Laboratories). The remainder, representing internalized (I) proteins, was incubated with $30 \mu \mathrm{l}$ of High Capacity NeutrAvidin Agarose Resin (Thermo Scientific) at $4^{\circ} \mathrm{C}$ overnight with gentle agitation. Beads were washed three times with PBS containing $1 \%$ Triton X-100, and bound proteins were eluted with $40 \mu$ l of $2 \times$ Laemmli sample buffer. An equal volume of internalized and total proteins was loaded per lane so that the loading of the internalized fraction was $\sim 5 \times$ that of total. Finally, proteins were separated by $8 \%$ or $10 \%$ SDS-PAGE gel and transferred to PVDF membranes (GE Healthcare). Immunoblotting was performed using appropriate antibodies against tags or specific proteins followed by HRP-conjugated secondary antibodies (Millipore) and detected by enhanced chemiluminescence (ECL Substrate, Thermo Scientific) using x-ray films (Kodak) or CCD camera (ImageQuant LAS 4000, GE Healthcare). Quantification was done using Image Quant software (GE Healthcare) based on intensity values of protein bands.

Surface biotinylation assay. Surface biotinylation was performed on $\mathrm{CHO}$ cells following established protocols (Duan et al., 2012). Cells were first incubated in $100 \mu \mathrm{M}$ dynasore for $30 \mathrm{~min}$ and then washed three times with the ice-cold PBS ${ }^{+/+}$solution, followed by addition of 0.25 $\mathrm{mg} / \mathrm{ml}$ Sulfo-NHS-LC-Biotin (Thermo Scientific) in the PBS ${ }^{+/+}$solution at $4^{\circ} \mathrm{C}$ for $30 \mathrm{~min}$. Unbound biotin group was quenched by a PBS $+/+$ solution that contained $0.1 \mathrm{M}$ glycine. Ten percent volume of the lysate was saved for determination of total $(\mathrm{T})$ proteins and mixed with $4 \times$ Laemmli sample buffer. The remainder, representing surface (S) proteins, was isolated by NeutrAvidin Agarose Resin and eluted as described above.

Subcellular fractionation. Subcellular fractionation was performed as described previously (Hallett et al., 2008). Briefly, the cerebral cortices from adult mouse brain were homogenized in TEVP buffer $(10 \mathrm{~mm}$ Tris-base, pH 7.4, 1 mm EDTA, 1 mm EGTA, $1 \mathrm{~mm} \mathrm{Na}_{3} \mathrm{VO}_{4}$, and $5 \mathrm{~mm}$ $\mathrm{NaF}$ ) containing $320 \mathrm{~mm}$ sucrose. The homogenate was centrifuged for 
$10 \mathrm{~min}$ at $800 \times \mathrm{g}, 4^{\circ} \mathrm{C}$, and then the supernatant ( $\mathrm{S}$, total soluble fraction) was collected. After centrifugation for $15 \mathrm{~min}$ at $9200 \times \mathrm{g}, 4^{\circ} \mathrm{C}$, the pellet (P2, crude synaptosomal membranes) was collected. The P2 was subsequently resuspended in TEVP buffer containing $35.6 \mathrm{~mm}$ sucrose and centrifuged for $20 \mathrm{~min}$ at $25,000 \times \mathrm{g}, 4^{\circ} \mathrm{C}$. The pellet (LP1, synaptosomal membranes) was resuspended for $30 \mathrm{~min}$ in $50 \mathrm{~mm}$ Trisbase solution containing $0.5 \%$ Triton X-100 and centrifuged for $20 \mathrm{~min}$ at $32,000 \times g, 4^{\circ} \mathrm{C}$, to collect the postsynaptic density (PSD) fraction.

Brain extracts, immunoprecipitation, and GST pull-down. Whole mouse brain or cerebral cortices were dissected rapidly on ice after decapitation. Brain tissues were homogenized (Homogenizer, Glas-Col) in co-IP buffer on ice. Homogenates were cleared by centrifugation and quantified using a protein-assay kit (Bio-Rad). All experiments were done using adult WT or KO male mice (2-3 months old). For co-IP, extracts from primary culture or isolated tissues were precleared with Protein G-Agarose (Roche) at $4^{\circ} \mathrm{C}$ for $2 \mathrm{~h}$. Then $5 \mu \mathrm{g}$ of desired antibodies or control normal IgG was added to the lysates and incubated with Protein G-agarose beads overnight at $4^{\circ} \mathrm{C}$. The next day, the beads were washed with the co-IP buffer. The immunoprecipitants were eluted using $2 \times$ Laemmli sample buffer and used for immunoblotting. For GST pull-down, the cytoplasmic domains of human ASICla were produced as GST-fusion proteins in Escherichia coli BL21 (DE3) pLysS (TIANGEN). GST-fusion proteins were purified under nondenaturing conditions using GST Bind kits (Novagen) in accordance with the manufacturer's instructions. Extracts from mouse cerebral cortices or $\mathrm{CHO}$ cells were incubated with the purified GST-fusion proteins or GST alone immobilized on glutathione-Sepharose 4B (GE Healthcare) beads at $4^{\circ} \mathrm{C}$ overnight in the co-IP buffer. The next day, the beads were thoroughly washed and the bound proteins eluted with the $2 \times$ Laemmli sample buffer and used for immunoblotting.

Immunocytochemistry. Cells were grown on glass coverslips and transfected as indicated. For the antibody feeding studies against external HA-tagged ASIC1a, cells were blocked (5\% FBS in PBS, 30 min at room temperature) and surface channels were labeled with a mouse anti-HA antibody (Covance) at $4^{\circ} \mathrm{C}$ for $1 \mathrm{~h}$. Unbound antibody was removed by washing three times with PBS. Surface-labeled channels were allowed to internalize for variable times at $37^{\circ} \mathrm{C}$. Cells were then fixed for $10 \mathrm{~min}$ with $4 \%$ paraformaldehyde $/ 4 \%$ sucrose/PBS on ice, and channels remaining at the surface $(S)$ were labeled with a saturating concentration of AlexaFluor-594-conjugated goat anti-mouse secondary antibody (Invitrogen). The fixed cells were then permeabilized by treatment with Triton X-100 (0.1\%, $10 \mathrm{~min}$ at room temperature). Internalized channels (I) that were already labeled at the cell surface with the HA antibody were detected with AlexaFluor-546-conjugated goat anti-mouse secondary antibody (Invitrogen). After extensive washing with PBS, the coverslips were mounted on glass slides with Fluorescent Mounting Medium (Dako).

Image acquisition and analysis. All images were acquired with a Zeiss 710 laser scanning confocal microscope with either a $40 \times($ NA 1.30) or a $63 \times$ (NA 1.40) oil-immersion lens. Images for all conditions in a particular experiment were obtained using identical acquisition parameters (e.g., gain, offset, laser power, pinhole size, scan speed) and were analyzed with ImageJ (National Institutes of Health) software using identical parameters. Cells from the same culture preparation were treated with drugs or vehicle control and compared with one group to another. To measure the number of puncta in antibody feeding assay, images from each experiment were converted to binary images by using a fixed threshold (100-255) of fluorescence intensity. The edge of each cell was outlined by GFP fluorescence and converted to mask. The puncta $(>0.1$ $\mu \mathrm{m}^{2}$ ) within each cell were then counted and measured in the binary images by ImageJ. To analyze the fluorescence level of endogenous AP2 $\mu 2$, fluorescence intensity was measured within each GFP neuron that was converted to mask as described above.

Electrophysiology. Whole-cell recordings from cultured cortical neurons (DIV 9-12) or CHO cells were performed by Axopatch 200B with Digidata $1440 \mathrm{~A}$ and the pClamp10 software (Molecular Devices). Recording pipettes were pulled to $4-6 \mathrm{M} \Omega$ when filled with the internal solution that contained the following (in $\mathrm{mm}$ ): $120 \mathrm{KCl}, 30 \mathrm{NaCl}, 0.5$ $\mathrm{CaCl}_{2}, 1 \mathrm{MgCl}_{2}, 5$ EGTA, $2 \mathrm{MgATP}$, and 10 HEPES, pH 7.2, and placed in the standard extracellular solution that contained the following (in $\mathrm{mm}$ ): $150 \mathrm{NaCl}, 5 \mathrm{KCl}, 1 \mathrm{MgCl}_{2}, 2 \mathrm{CaCl}_{2}, 10$ glucose, and 10 HEPES (buffered to various $\mathrm{pH}$ values with $\mathrm{NaOH}$ or $\mathrm{HCl}$ ). Cells were recorded at a holding potential of $-60 \mathrm{mV}$. A "Y-tube" system was used to achieve a rapid exchange of extracellular solutions. ASIC1a channels were activated by a drop in $\mathrm{pH}$ from 7.4 to $\mathrm{pH} 6.0$ every $3 \mathrm{~min}$ to allow a complete recovery of the channel from desensitization (Duan et al., 2012). All the experiments were performed at room temperature $\left(22^{\circ} \mathrm{C}-25^{\circ} \mathrm{C}\right)$.

Acid-induced neuronal damage. Cultured cortical neurons were randomly divided into designated experimental groups at DIV 14-16. Dynasore $(100 \mu \mathrm{M})$ was added $30 \mathrm{~min}$ before acidosis. Neurobasal medium was removed before washing cells twice with the standard extracellular solution. Cells were incubated in normal ( $\mathrm{pH}$ 7.4) or acidic, $\mathrm{pH} 6.0$, extracellular solution for $1 \mathrm{~h}$. Then the culture medium was returned to cells after acidosis. The cells were allowed to recover for $24 \mathrm{~h}$ at $37^{\circ} \mathrm{C}$ with $5 \% \mathrm{CO}_{2}$. Cell viability was assessed by propidium iodide (PI, Sigma) staining and the cell titer blue (CTB) assay. Briefly, cells were stained with PI $(10 \mu \mathrm{g} / \mathrm{ml})$ for $10 \mathrm{~min}$ at room temperature $\left(22^{\circ} \mathrm{C}-25^{\circ} \mathrm{C}\right)$ and then observed by fluorescence microscopy. Cell morphology observed through DIC was used to distinguish neurons from glia. The CTB assay was performed using CTB reagent (Promega) in accordance with the manufacturer's instruction. To evaluate the effects of psalmotoxin 1 (PcTX1), a saturate concentration of the peptide $(0.2 \mu \mathrm{M})$ was added 30 min before and during acidosis.

Reagents. All the drugs were purchased from Sigma, except for those mentioned otherwise. PcTX1 was purchased from the Peptide Institute. The following antibodies were used: goat anti-ASIC1a (1:500, Santa Cruz Biotechnology), mouse anti-GFP (1:500, Roche), mouse anti-transferrin receptor (TfR) (1:500, Invitrogen), mouse anti-GST (1:2000, Merck), rabbit anti-dynamin 1 (1:1000, Bioworld), mouse anti-AP2 $\alpha$ (1:200, Sigma), mouse anti-AP2 $\mu 2$ (1:500, BD Biosciences), goat anti-PICK1 (1:1000, Santa Cruz Biotechnology), rabbit anti-clathrin heavy chain (CHC) (1:1000, Cell Signaling Technology), mouse anti-GAPDH (1: 4000 , Kang Chen), mouse anti- $\alpha$ tubulin (1:4000, Sigma), mouse antiactin (1:4000, Sigma), and rabbit anti-PSD95 (1:2000, Epitomics).

Statistical analysis. Results are expressed as mean \pm SEM. Statistical comparisons were performed by two-tailed Student's paired or unpaired $t$ test when comparing two groups and by one-way randomized ANOVA, followed by Tukey post hoc tests when comparing multiple groups. $p$ values of $<0.05$ were considered statistically significant.

\section{Results}

\section{ASIC1a undergoes constitutive internalization}

To examine whether ASICs could undergo constitutive endocytosis, we first performed an antibody feeding assay to visualize the internalized ASIC1a (for details, see Materials and Methods). A recombinant ASIC1a that contained an extracellular HA tag between ${ }^{147} \mathrm{~F}$ and ${ }^{148} \mathrm{~K}$ was used because the antibody against extracellular epitope of endogenous ASIC1a is unavailable. Despite a decreased proton affinity compared with the WT ASIC1a (Chen and Grunder, 2007), insertion of the HA tag did not obviously affect the surface expression of ASIC1a (Duan et al., 2012). To measure constitutive endocytosis, $\mathrm{CHO}$ cells expressing HAASIC1a-GFP were prelabeled with an anti-HA antibody for $1 \mathrm{~h}$ at $4^{\circ} \mathrm{C}$ and endocytosis was triggered by raising the temperature to $37^{\circ} \mathrm{C}$ for desired time periods. To distinguish the surface-labeled and internalized HA-ASIC1a-GFP, the cells were fixed briefly without permeabilization and a saturating concentration of AlexaFluor-594-conjugated goat anti-mouse secondary antibody was applied to label all surface anti-HA antibodies. This was followed by permeabilization and staining with the AlexaFluor-546conjugated goat anti-mouse secondary antibody to label the remaining (internalized) anti-HA antibodies. As shown in Figure $1, A$ and $B$, ASIC1a underwent constitutive endocytosis in a timedependent manner. As negative controls, nonpermeabilized cells or permeabilized cells without prelabeling by the anti-HA anti- 
A

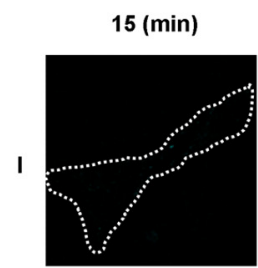

$\mathbf{S}$
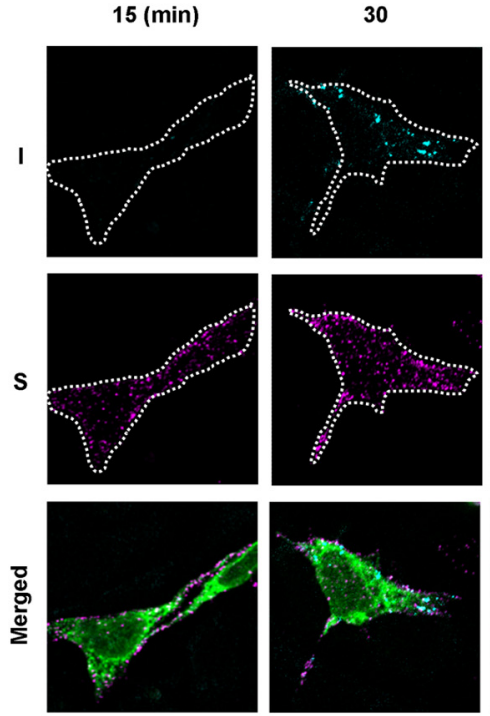

HA-ASIC1a-GFP
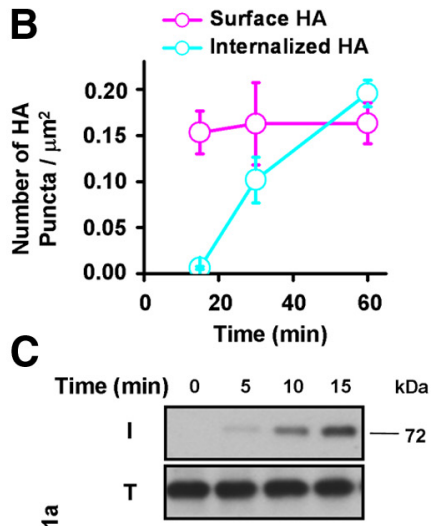

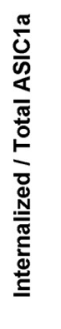

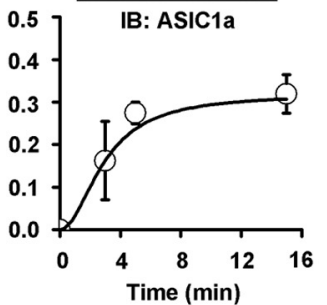

60
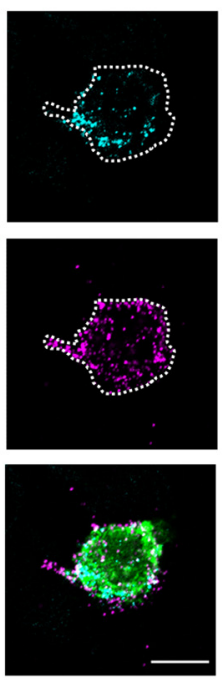

Figure 1. ASIC1a undergoes constitutive internalization. $\boldsymbol{A}$, Internalization of ASIC1a expressed in CHO cells. HA-ASIC1a-GFP expressed on the surface of $\mathrm{CHO}$ cells was labeled with a mouse anti-HA antibody and then allowed to internalize for 15, 30, or 60 min. Surface HA-ASIC1a (S) channels were labeled with a saturating concentration of AlexaFluor-594-conjugated secondary antibody. Internalized channels (I) were detected with AlexaFluor-546-conjugated secondary antibody after cell permeabilization. The edge of each cell was outlined by GFP fluorescence. Scale bar, $10 \mu \mathrm{m} . \boldsymbol{B}$, The numbers of HA puncta per cell area $\left(\mu \mathrm{m}^{2}\right)$ for both surface expressed and internalized channels were quantified and shown in the time course plots (mean \pm SEM, $n=15-29$ cells for each condition). C, Time course of internalization of native ASIC1a in cultured rat cortical neurons (DIV 10-12). Channels present on the cell surface were biotinylated and then allowed to internalize for the indicated times, after which the remaining surface biotin was stripped off. The internalized biotinylated ASIC1a was detected by precipitation of cell lysates using NeutrAvidin agarose, followed by immunoblotting (IB). Top, Representative Western blots of internalized (I) and total (T) ASIC1a. Bottom, Quantification of the ratio of internalized/total ASIC1a by fitting with a single exponential growth curve, which generated the time constant $(\tau)$ of ASIC1a internalization (7.0 $\pm 1.5 \mathrm{~min}, n=4)$.

body did not show any staining by Alexa-546 (data not shown), demonstrating the specificity of Alexa-546 label at the internalized HA-ASICla-GFP.

Second, we assayed the rate of constitutive endocytosis of endogenous ASICla in cultured cortical neurons based on internalization of surface-biotinylated ASICla proteins (see Materials and Methods). Briefly, cells were biotinylated under nonpermeabilized conditions and then allowed to undergo endocytosis for a desired period of time. At the end of incubation, surface biotins were stripped off and internalized ASICla was detected by precipitation of cell lysates using NeutrAvidin agarose followed by immunoblotting with an anti-ASIC1a antibody. The stripping protocol was effective to exclude the contamination from biotinylated proteins remaining on the surface (data not shown). Images in Figure $1 C$ show the time courses of internalized as well as the total endogenous ASICla in cultured cortical neurons. Fitting the ratio of internalized/total ASIC1a levels by a single exponential growth curve indicated that the internalization rate of ASICla reached an apparent maximum by $15 \mathrm{~min}$, with a time constant $(\tau)$ of $7.0 \pm 1.5 \mathrm{~min}$ (Fig. 1C, bottom). These data demonstrate the existence of basal ASICla internalization both in the heterologous system and in native neurons.

ASIC1a is associated with endocytic complex and internalized via the clathrin-dependent pathway

To identify interacting proteins that may regulate ASIC1a function, we have performed a GST pull-down based mass spectros- copy (MS) screening on mouse brain extracts using the cytoplasmic domains of ASICla fused with GST. Proteins copurified with GST-ASICla cytoplasmic domains were evaluated by SDS gel electrophoresis and visualized by Coomassie blue staining (Fig. 2A). Among the bands that were pulled down by GSTASIC1a C terminus (CT) but not GST alone or the lysis buffer without the brain extracts (-), which should represent proteins that specifically interacted with the ASIC1a-CT, a $\sim 100 \mathrm{kDa}$ band was reproducibly identified in three independent experiments (Fig. $2 A$, arrow). MS analysis of peptide fragments derived from this band identified AP2 $\alpha 2$ and $\beta 1$ subunits (Fig. 2B).

AP2 is well known to be involved in vesicle-mediated protein transport, particularly clathrin-dependent endocytosis, in which protein cargos internalized to the clathrin-coated vesicles are mainly selected by the AP2 complex that binds to their cytoplasmic domains (McMahon and Boucrot, 2011). Identification of $\mathrm{AP} 2 \alpha 2$ and AP $2 \beta 1$ as proteins that bind to the cytoplasmic C terminus of ASICla suggested that ASICla could undergo endocytosis via the clathrin-dependent pathway, a conclusion that is also supported by the previous finding that endocytosis of a related channel, $\mathrm{ENaC}$, is clathrin-dependent (Wang et al., 2006). To confirm the association between ASIC1a and endocytic complex, we performed co-IP and found that the ASICla antibody precipitated $\mathrm{CHC}, \mathrm{AP} 2 \alpha$, and $\mathrm{AP} 2 \mu 2$ from cerebral cortices prepared from WT but not ASICla KO mice (Fig. 2C). Likewise, the association between ASIC1a and AP2 $\alpha$ was confirmed by co-IP using the anti-GFP antibody in CHO cells stably expressing GFP-ASIC1a (data not shown), demonstrating that the association between ASICla and adaptor protein complex is intrinsic to these proteins. These results provided additional support on association of ASICla with the adaptor protein complex.

If ASIC1a is associated with AP2 and clathrin, then a substantial amount of native ASIC1a proteins should coexist with these endocytic proteins in subcellular fractions. Therefore, we next examined the distribution of ASICla proteins in subcellular fractions prepared from mouse cerebral cortices by differential centrifugations. Although ASICla proteins were detected in all fractions, a substantial amount was found in the purified synaptosomal membrane (LP1) fraction, which was also highly enriched with $\mathrm{CHC}$ and the core subunits of $\mathrm{AP} 2, \mathrm{AP} 2 \alpha$ and $\mathrm{AP} 2 \mu 2$ (Fig. 2D). PSD95, a PSD marker, was enriched in the PSD fraction (Fig. 2D), demonstrating the successful isolation of different subcellular components from the mouse brain. Collectively, these data show that ASIC1a in mouse brain forms a complex with adaptor proteins and is likely internalized via the clathrinmediated pathway.

To further examine the dependence of ASIC1a internalization on the clathrin pathway, we first blocked the clathrin-dependent endocytosis with a small molecular inhibitor, Tyr A23. As ex- 

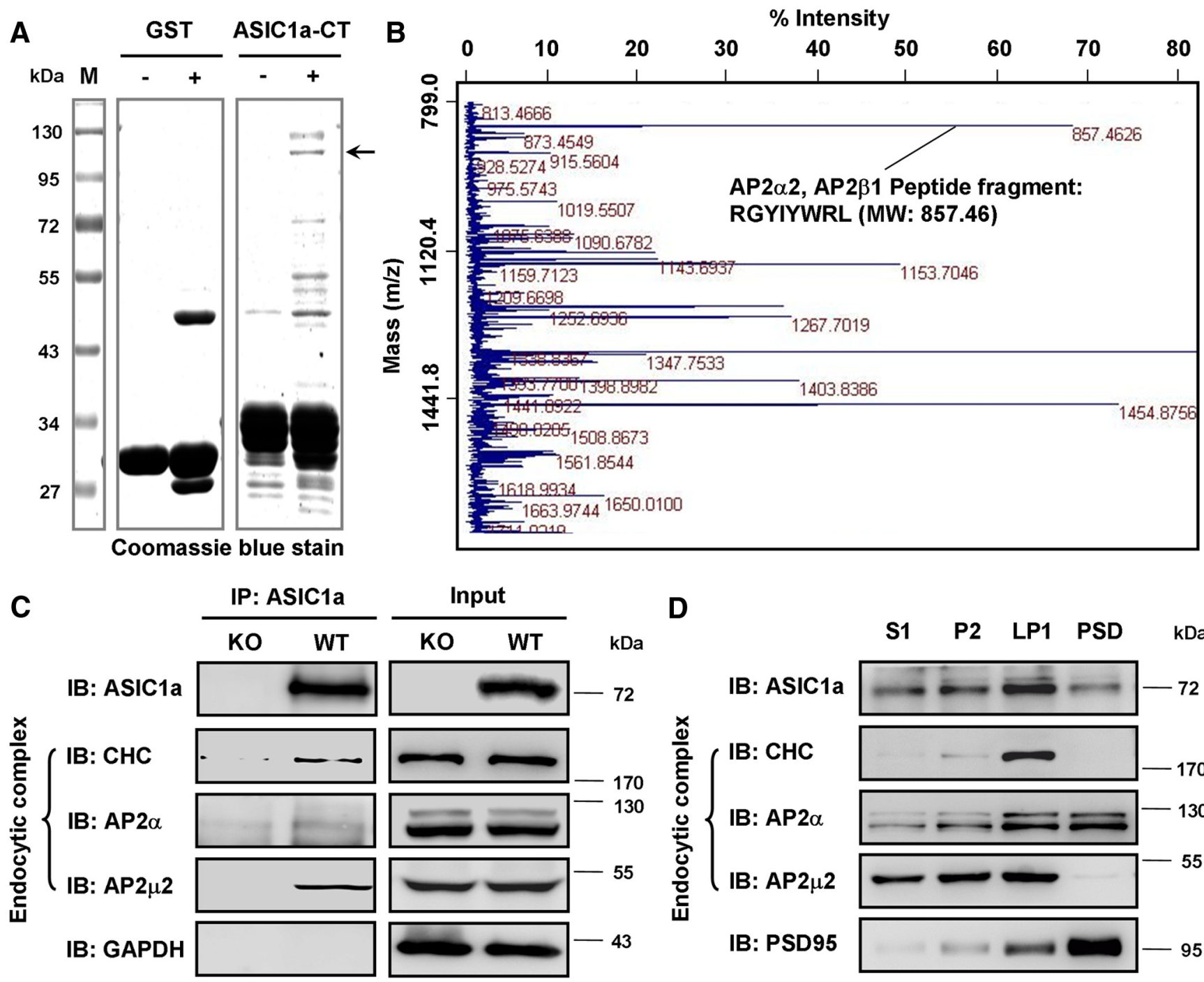

D

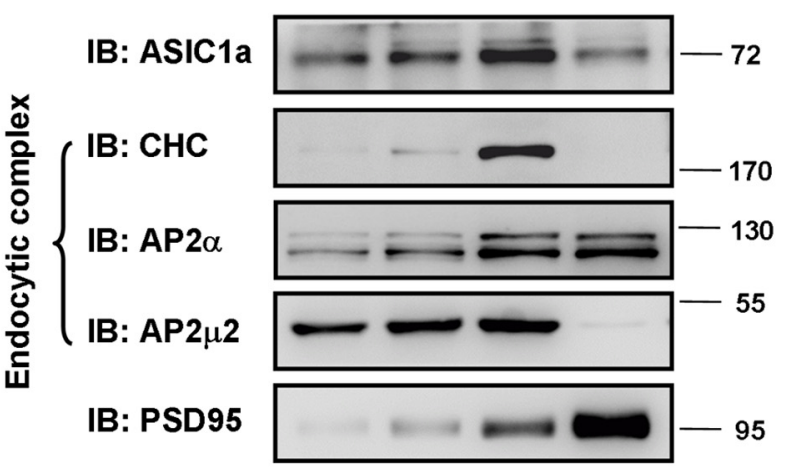

Figure 2. ASIC1a is associated with endocytic complex in the brain. A, Purified GST or GST-ASIC1a C terminus (ASIC1a-CT) was incubated with $(+)$ or without $(-)$ mouse brain extracts. Bound proteins were separated by SDS-PAGE and visualized via Coomassie blue staining. Arrow indicates the AP2 protein complex-containing band $(\sim 110 \mathrm{kDa})$ that was reproducibly identified in three independent experiments. M, Molecular weight markers. $\boldsymbol{B}$, Bands of interest from $\boldsymbol{A}$ were excised from the gel, trypsin-digested, and analyzed by matrix-assisted laser desorption/ionization time of flight mass spectrometry (MALDI-TOF-MS) analysis. MS sequencing of peptides (MW $=857.46$, RGYIYWRL) from the indicated band identified AP2 $\alpha 2$ (GenBank accession no. P17427) and AP2 $\beta 1$ (GenBank accession no. Q9DBG3). C, Co-IP results from cerebral cortices of WT and ASIC1a K0 mice. CHC, AP2 $\alpha$, and AP2 $\mu 2$ were detected by immunoblotting (IB) from immunoprecipitation by anti-ASIC1a antibody. No ASIC1a-positive band was detected from the KO lane, which validates the specificity of the ASIC1a antibody for biochemical experiments. Results are representatives of three independent experiments. D, ASIC1a is associated with the endocytic complex in subcellular fractionation from mouse cerebral cortices. Representative images of $I B$ of subcellular fractions show the distribution profiles of indicated proteins. S1, Supernatant from homogenate centrifuged for $10 \mathrm{~min}$ at $800 \times g$, which represents the total soluble fraction; P2, pellet from S1 centrifuged for 15 min at $9200 \times g$, which represents the crude synaptosomal membranes; LP1, pellet from resuspended P2 centrifuged for 20 min at $25,000 \times g$, which represents the synaptosomal membranes. PSD fraction was isolated from LP1. Results are representatives of three independent experiments.

pected, treatment with Tyr A23 caused a $59.4 \pm 7.7 \%$ decrease in the internalization of surface biotinylated GFP-ASICla compared with the Veh (Fig. 3A). Under the same conditions, the internalization of TfR was decreased even more ( $2.5 \pm 1.4 \%$ of Veh) (Fig. $3 A)$, consistent with a previous study (Banbury et al., 2003). These data indicated the clathrin-dependent pathway plays a major part in the regulation of constitutive ASICla internalization; however, a clathrin-independent pathway may also be involved.

Second, to examine the role of AP2 complex in regulating endocytosis of ASICla, multiple shRNA constructs were designed to reduce AP2 $\mu 2$ (a core subunit of adaptor protein complex) expression in mouse cortical neurons. One of them $(\operatorname{shAP} 2 \mu 2)$ efficiently reduced the expression of mCherryAP2 $\mu 2$ in transfected CHO cells ( $16.6 \pm 5.5 \%$ of scrambled control) and that of endogenous AP2 $\mu 2$ in mouse cortical neurons
$(1.7 \pm 1.1 \%$ of scrambled control) (Fig. 3B-D). We then used whole-cell recordings to examine the effects of AP2 $\mu 2$ knockdown on ASIC1a channel activity. Previous studies have demonstrated that ASICla is responsible for proton ( $\mathrm{pH}$ 6.0)-activated currents in cortical neurons because genetic ablation of ASIC1a completely abolished the $\mathrm{pH}$ 6.0-activated currents (Xiong et al., 2004; Duan et al., 2011). In mouse cortical neurons transfected with shAP $2 \mu 2$, proton-activated current density was significantly higher than that transfected with the scrambled control vector (Scr) (shAP2 $\mu 2: 37.2 \pm 4.2$ pA/pF; Scr: $24.5 \pm 2.0$ pA/pF) (Fig. $3 E)$. There was no change in the decay time constant $(\tau)$ of current (shAP2 $\mu 2: 2.3 \pm 0.2 \mathrm{~s} ; \mathrm{Scr}: 2.3 \pm 0.1 \mathrm{~s}$ ), suggesting that the enhancement was unlikely the result of a change in channel gating. These data are consistent with enhanced surface density of the ASIC1a channels because of AP2 $\mu 2$ knockdown and thus 
A

IB: ASIC1a

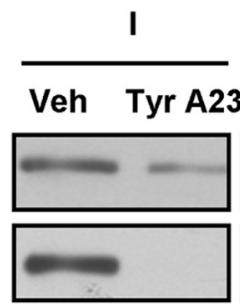

T

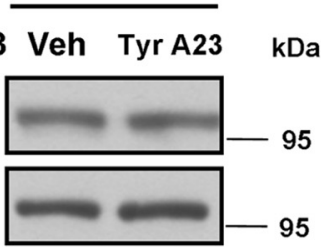

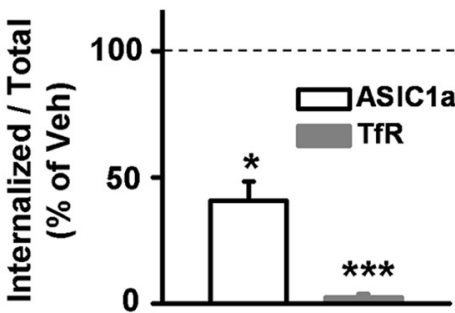

Tyr A23
B

\section{IB: AP $2 \mu 2$ \\ IB: Actin}

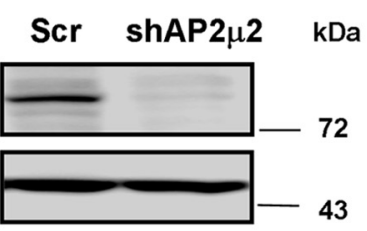

D

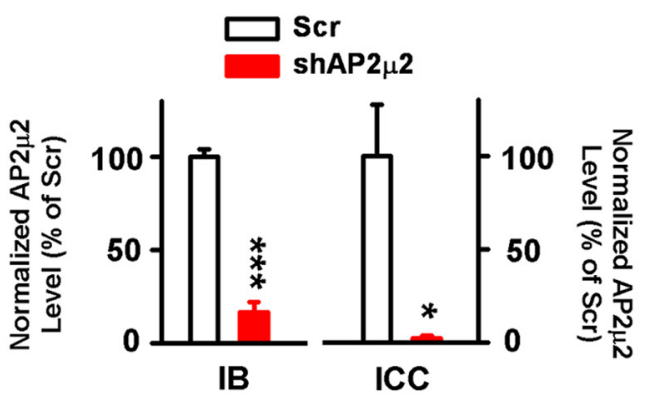

C
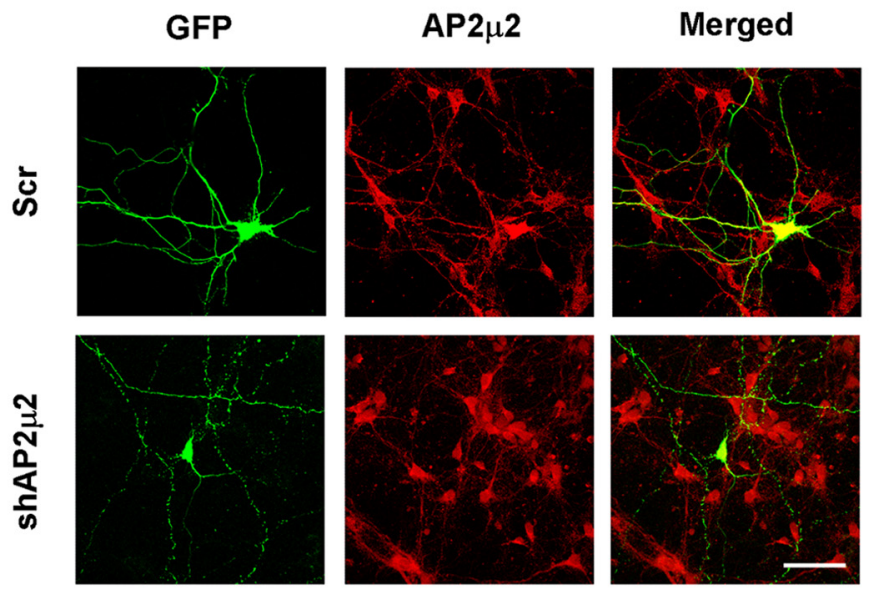

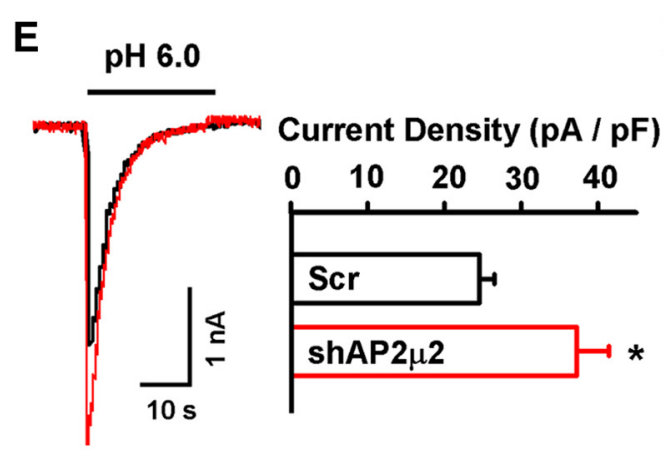

F

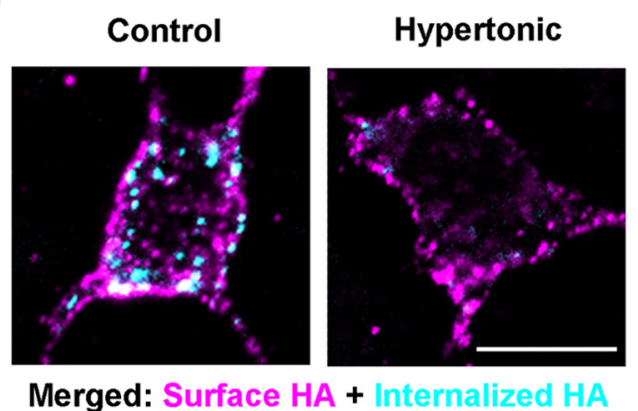

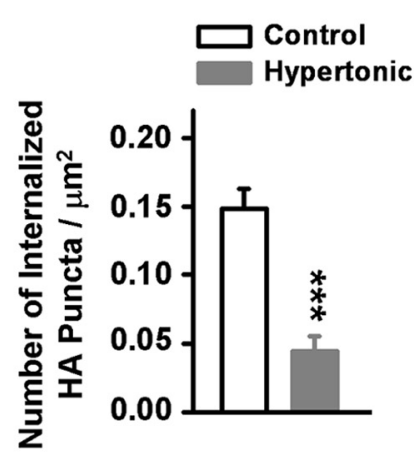

Figure 3. ASIC1a is mainly internalized by the clathrin-mediated pathway. A, The endocytosis of ASIC1a was inhibited by tyrphostin A23 (TyrA23). TfR was used as a positive control. Internalization assay was performed at $37^{\circ} \mathrm{C}$ for 15 min using $\mathrm{CHO}$ cells stably expressing GFP-ASIC1a ( $\left.\sim 100 \mathrm{kDa}\right)$. All the drugs were applied to the culture medium 30 min before the internalization assay. Vehicle (Veh): $0.35 \%$ (v/v) DMSO alone; TyrA23: $350 \mu \mathrm{m}$ tyrphostin A23. I, Internalized; $\mathrm{T}$, total; IB, immunoblotting. Right, Data are mean \pm SEM of internalized/total based on band intensities and normalized to Veh-treated cells (hyphenated line). ${ }^{*} p<0.05$ versus the corresponding Veh control (paired $t$ test). ${ }^{* * *} p<0.001$ versus the corresponding Veh control (paired $t$ test). $n=3$ and 5 for ASIC1a and TfR, respectively. $\boldsymbol{B}$, Representative blots showing that the shRNA construct effectively knocked down mouse AP2 $\mu 2$ expression in transfected CHO cells. Cells were cotransfected with mCherry-AP2 $\mu 2$ and shAP2 $\mu 2$ or scrambled vector (Scr). Proteins were immunoblotted for AP2 $\mu 2(\sim 80 \mathrm{kDa}$, mCherry-AP2 $\mu 2)$ and actin $(\sim 45 \mathrm{kDa})$. C, Representative images of immunocytochemical staining of AP2 $\mu 2$ (red) with anti-AP2 $\mu 2$ antibody in mouse cortical neurons (DIV 7) that expressed shAP $2 \mu 2$ or Scr vector for $2 \mathrm{~d}$. Transfected cells were identified by the expression of GFP (green) included in the same vectors. The neuron that expressed shAP2 $\mu 2$ showed a marked decrease in endogenous AP2 $\mu 2$ staining (bottom) compared with the Scr-transfected neuron (top). Scale bar, $50 \mu \mathrm{m}$. D, Summary data for $\boldsymbol{B}$ and $\boldsymbol{C}$ normalized to intensity values of AP2 $\mu 2$ in Scr-transfected cells obtained from immunoblotting (IB) or immunocytochemistry (ICC). Data represent mean \pm SEM. ${ }^{* * *} p<0.001 . n=6$ for IB. ${ }^{*} p<0.05 . n=6$ and 9 for Scr and shAP2 $\mu 2$, respectively, for ICC. E, AP2 $\mu 2$ knockdown increased proton (pH 6.0)-activated currents. Cultured mouse cortical neurons were transfected with shAP $2 \mu 2$ or Scr at DIV 7, and proton-activated currents were recorded 2-3 d later. Left, Representative current traces for shAP2 $\mu 2$ (red) or Scr (black) transfected neurons. Right, Summary data for proton-activated current density (mean \pm SEM). ${ }^{*} p<0.05$ (unpaired $t$ test). $n=9$ and 11 for Scr and shAP2 $\mu 2$, respectively. $F$, Blockade of ASIC1a internalization by hypertonic treatment. The experiment was performed and quantified as that in Figure $1, A$ and $B$. Internalization of HA-ASIC1a-GFP expressed in CHO cells was allowed to proceed for $1 \mathrm{~h}$ in control or a hypertonic buffer (hypertonic, $0.45 \mathrm{~m}$ sucrose in the medium). The surface HA-ASIC1a was labeled by AlexaFluor-594 (magenta), whereas the internalized HA antibody was recognized by AlexaFluor-546 (cyan). Scale bar, $10 \mu \mathrm{m}$. Data at right represent mean $\pm S E M$. ${ }^{* * *} p<0.001$ (unpaired $t$ test). $n=23$ and 25 for control and hypertonic, respectively.

support a critical role of the AP2 complex in ASIC1a internalization in neurons.

Third, hypertonic treatment has been shown to inhibit receptormediated endocytosis of several membrane proteins by blocking the formation of clathrin-coated pits (Daukas and Zigmond, 1985; Heuser and Anderson, 1989). As expected, cells treated with a hypertonic medium showed less internalized puncta for HA staining (control, $0.15 \pm 0.01$ internalized puncta/ $\mu \mathrm{m}^{2}$; hypertonic, $0.04 \pm 0.01$ internalized puncta $\left./ \mu \mathrm{m}^{2}\right)$ in antibody feeding assay performed on $\mathrm{CHO}$ cells expressed HA-ASIC1a-GFP (Fig. 3F). These results further support the notion that ASICla is internalized mainly via the clathrinmediated pathway. 
ASIC1a is internalized in a dynamin-dependent manner

Dynamin is reported to play an important role in the vesicle scission reaction after cargo internalization, making it indispensable for both clathrin-dependent and -independent endocytosis (Praefcke and McMahon, 2004). Mutations of lysine 44 in the GTP-binding domain of dynamin (K44A or K44E) abolished clathrinmediated endocytosis of TfRs and epidermal growth factor receptors (van der Bliek et al., 1993; Damke et al., 1994). Given that dynamin 1 represents the major dynamin isoform expressed in the nervous system (Ferguson et al., 2007), we tested the role of dynamin 1 in the regulation of ASIC1a internalization. First, we showed by co-IP that ASIC1a is associated with dynamin 1 in $\mathrm{CHO}$ cells coexpressing these two proteins (Fig. $4 A$ ), suggesting a potential role of dynamin 1 in the regulation of ASIC1a. Second, we examined the effects of WT and dominant-negative (DN) dynamin1 K44A on whole-cell ASICla currents as a way to infer surface density. $\mathrm{CHO}$ cells expressing dynamin 1 K44A showed little positive puncta $\left(0.02 \pm 0.005\right.$ internalized puncta/ $\left.\mu \mathrm{m}^{2}\right)$ compared with the vector control group $\left(0.17 \pm 0.01\right.$ internalized puncta/ $\left.\mu \mathrm{m}^{2}\right)$ and WT dynamin 1 group $(0.14 \pm 0.007$ internalized puncta/ $\mu \mathrm{m}^{2}$ ) in transferrin uptake assay, suggesting that the dynamin-dependent endocytosis was effectively blocked (data not shown). As expected, proton-activated currents were increased in $\mathrm{CHO}$ cells cotransfected with ASIC1a and dynamin1 K44A (274.9 \pm $40.2 \mathrm{pA} / \mathrm{pF})$ compared with the vector control group $(154.1 \pm 21.4 \mathrm{pA} / \mathrm{pF})$ and WT dynamin 1 group $(129.5 \pm 17.1 \mathrm{pA} /$ pF) (Fig. 4B,C). Similarly, protonactivated current density in primary cultures of mouse cortical neurons was also increased with the transfection of dynamin1 K44A (39.8 $\pm 6.3 \mathrm{pA} / \mathrm{pF})$ compared with that of the vector control $(20.8 \pm 3.8 \mathrm{pA} / \mathrm{pF})$ and WT dynamin 1 $(22.0 \pm 2.4 \mathrm{pA} / \mathrm{pF})$ (Fig. 4D). Thus, blocking the constitutive endocytosis of ASIC1a with the dominantnegative dynamin1 K44A led to enhanced ASIC1a channel activity, likely resulting from increased surface density of ASIC1a proteins.

To confirm that dynamin plays a role in ASIC1a endocytosis, we measured the internalization of surface biotinylated ASIC1a in $\mathrm{CHO}$ cells. Treatments with the small-molecule dynamin inhibitor, dynasore (Macia et al., 2006), markedly blocked the endocytosis of GFP-ASICla in contrast with vehicle control (Veh) $(24.2 \pm 4.9 \%$ of Veh) (Fig. $4 E$ ). As a positive control, the endocytosis of TfR was also abolished by the dynasore treatment (data not shown). Conversely, dynasore also increased surface retention of GFP-ASIC1a in these cells (140.0 $\pm 9.7 \%$ of Veh)
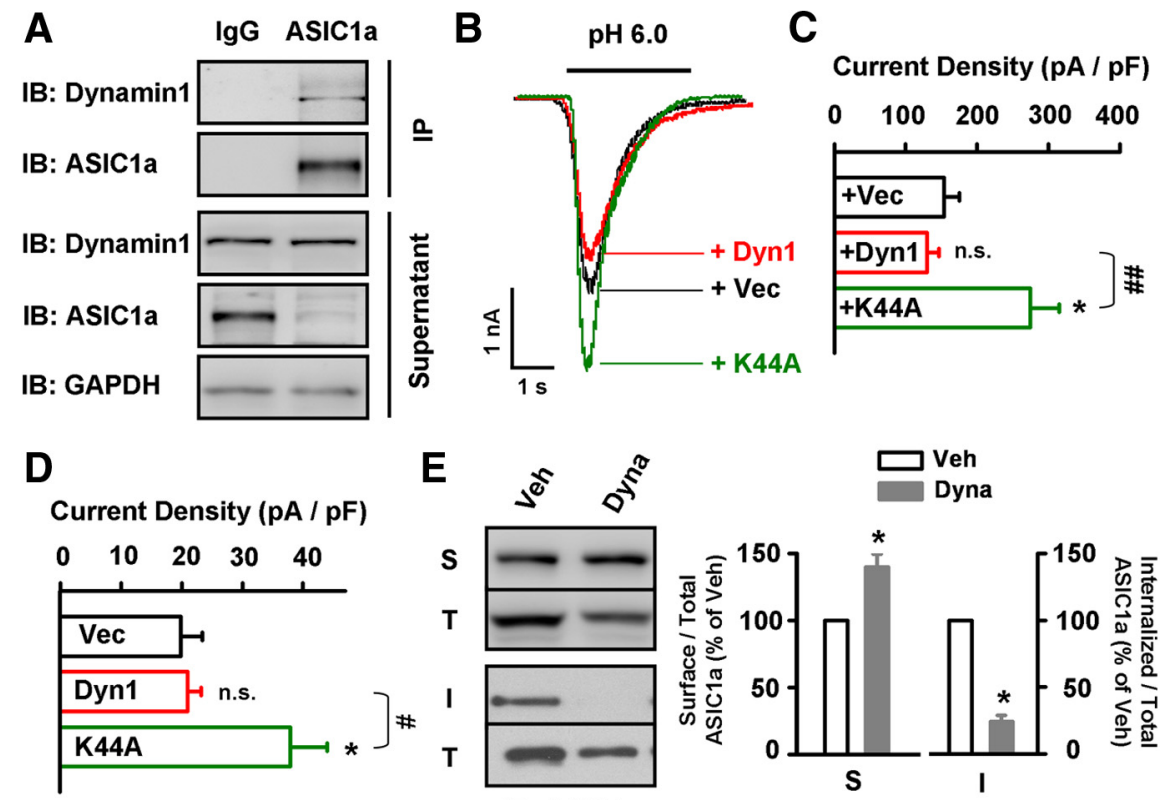

IB: ASIC1a
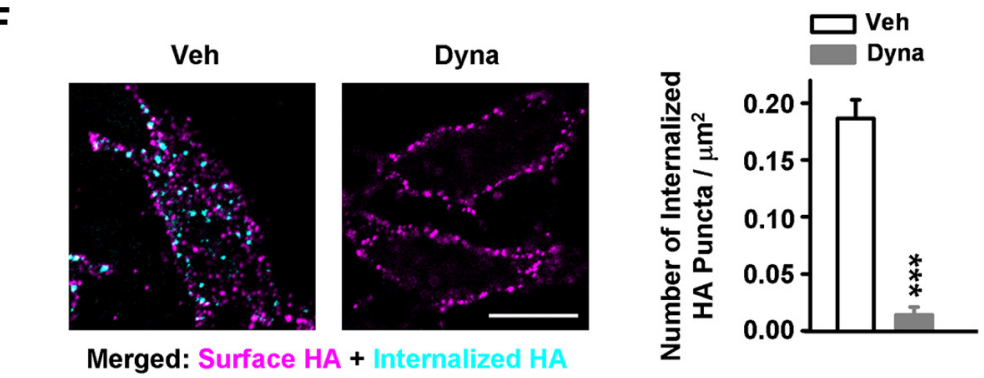

Figure 4. ASIC1a is internalized by the dynamin-dependent pathway. A, Co-IP results from CHO cells cotransfected with GFP-ASIC1a ( $\sim 100 \mathrm{kDa}$ ) and GFP-dynamin $1(\sim 140 \mathrm{kDa})$ showing that dynamin1 was physically associated with ASIC1a. Results are representatives of three independent experiments. $\boldsymbol{B}$, Proton-activated currents in $\mathrm{CHO}$ cells that coexpressed ASIC1a with GFP proton-activated current density in $\mathrm{CHO}$ cells transfected as in $\boldsymbol{B}$. Data are mean \pm SEM. ${ }^{*} p<0.05$ versus Vec (ANOVA). ${ }^{\# \#} p<$ 0.01 , K44A versus Dyn1 (ANOVA). n.s., Not significant. $n=9,8$, and 13 for Vec, Dyn1, and K44A, respectively. D, Summary of proton-activated current density of cultured mouse cortical neurons transfected with GFP vector, WT dynamin1, or DN dynamin1 K44A at DIV $7-8$ and recorded $1 \mathrm{~d}$ later. Data are mean \pm SEM. ${ }^{*} p<0.05$ versus Vec (ANOVA). ${ }^{\#} p<0.05$, K44A versus Dyn 1 GFP-ASIC1a stably expressed in CHO cells. Vehicle [Veh, $0.1 \%$ (v/v) DMSO alone] or dynasore (Dyna, $100 \mu \mathrm{m}$ ) was applied to the culture medium 30 min before the biotinylation assay. Surface expressed (S), internalized (I), and total (T) GFP-ASIC1a were sponding Veh controls. ${ }^{*} p<0.05$ versus Veh (paired $t$ test). $n=5$ for surface biotinylation assay; $n=3$ for biotinylated endocytosis assay. $\boldsymbol{F}$, Dynasore blocked the endocytosis of ASIC1a in antibody feeding assay. The experiment was performed and presence of Veh $(0.1 \%$ DMSO) or dynasore (Dyna, $100 \mu \mathrm{m})$. The surface HA-ASIC1a was labeled by AlexaFluor-594 (magenta), whereas the internalized HA antibody was recognized by AlexaFluor-546 (cyan). Scale bar, $10 \mu \mathrm{m}$. Right, Data are mean \pm SEM. ${ }^{* * *} p<0.001$ (unpaired $t$ test). $n=13$ and 10 for Veh and Dyna, respectively.

(Fig. 4E). In antibody feeding assay performed on $\mathrm{CHO}$ cells expressing HA-ASICla-GFP, we showed that cells treated with dynasore for $1 \mathrm{~h}$ had little internalized puncta for HA staining, in contrast to the vehicle control (Veh, $0.18 \pm 0.02$ internalized puncta $/ \mu \mathrm{m}^{2}$; Dyna, $0.02 \pm 0.01$ internalized puncta $/ \mu \mathrm{m}^{2}$ ) (Fig. $4 F)$. These data indicate that ASICla is internalized via a dynamin-dependent pathway.

Specific interaction between a C-terminal noncanonical endocytic motif of ASIC1a and the endocytic complex The AP2 complex is known to play a core role in cargo selection during clathrin-dependent endocytosis by interacting directly with motifs in the cytoplasmic domains of transmembrane recep- 


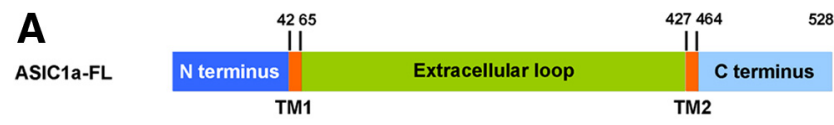

GST-ASIC1a-NT GST - MELKAEEEEVGGVQPVSIQAFASSSTLHGLAHIFSYERLSL
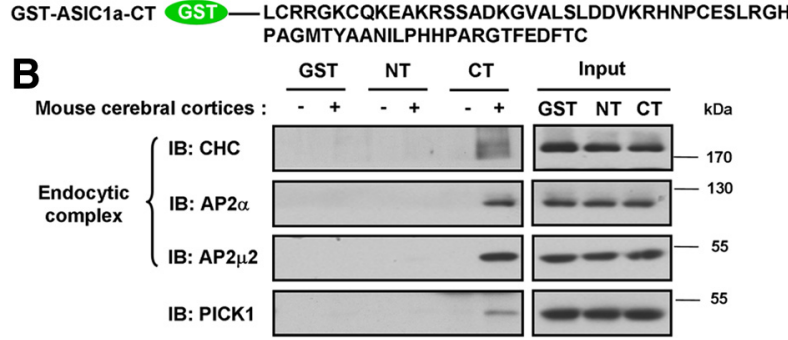

Figure 5. The C terminus of ASIC1a interacts with the endocytic complex. A, Diagram of cytoplasmic ASIC1a constructs fused to GST. The red characters at the $\mathrm{N}$ terminus of ASIC1a resemble the YXXØ endocytic motif. FL, Full-length; NT, N terminus; CT, C terminus. B, Interaction between ASIC1a-CT and the endocytic complex in mouse cerebral cortices. GST and GSTfusion proteins of ASIC1a-NT and ASIC1a-CT were incubated with $(+)$ or without $(-)$ cerebral cortex extracts in a GST pull-down assay. GST alone served as a negative control. Components of the endocytic complex (CHC, AP2 $\alpha$, and AP2 $\mu 2$ ) were examined by immunoblotting (IB). PICK1 binding with the C terminus of ASIC1a served as a positive control. Results are representatives of three independent experiments.

tors through their $\mu$ - and $\sigma$-subunits, and indirectly with cargos using its appendage domains to bind other specific adaptor proteins (McMahon and Boucrot, 2011). Given that components of the endocytic complex (CHC, AP2 $\alpha, \mathrm{AP} 2 \mu 2)$ coexist with ASIC1a in synaptosomal membrane (LP1) fraction and can be coimmunoprecipitated from mouse cerebral cortices using antibody against ASICla (Fig. 2C,D), we explored the binding of these adaptor proteins to the cytoplasmic domains of ASIC1a using the GST pull-down assay. Amino acid sequences included in the GST-ASIC1a N terminus (NT) and GST-ASIC1a-CT are shown in Figure 5A. The ASIC1a-NT contains a putative conventional endocytic motif YERL, which resembles the AP2 $\mu 2$ subunit binding motif YXXØ (Traub, 2009). To our surprise, ASICla-CT, but not ASIC1a-NT, interacted with the endogenous endocytic complex components, including $\mathrm{CHC}, \mathrm{AP} 2 \alpha$, and AP2 $\mu 2$ from mouse cerebral cortices (Fig. 5B). PICK1, a well-characterized ASIC binding partner that binds to the $\mathrm{C}$ terminus of ASICs via its PDZ domain (Hruska-Hageman et al., 2002), was detected as a positive control (Fig. 5B). These data suggest that the ASIC1a-CT, but not ASIC1a-NT, specifically interacts with adaptor protein complex in the brain.

To define the sequence determinant responsible for the interaction with the adaptor protein complex, we tested a series of deletion mutants of the ASIC1a-CT (Fig. 6A) using the GST pulldown assay. Deletion of the first 16 amino acids $(\Delta 465-480)$ of ASIC1a-CT attenuated AP2 binding, but the other three truncations ( $\Delta 481-496, \Delta 497-512$, and $\Delta 513-528)$ did not affect AP2 pull-down from the mouse cerebral cortices (Fig. 6B). To narrow down the critical residues, sequential deletions of five amino acids within residues $465-480(\Delta 465-469, \Delta 470-474$, and $\Delta 475$ 480) were made (Fig. 6A). Strikingly, the most membraneproximal amino acids ${ }^{465}{ }^{2}$ CRRG ${ }^{469}$ of ASIC1a-CT were shown to be indispensable for AP2 pull-down (Fig. $6 B$ ). Moreover, mutating all five amino acids to alanines (465-469 A) led to a dramatic decrease in the interaction, and even mutating just the first three (465-467 A) also led to a detectable decrease in the interaction despite being less effective than mutating five (Fig. 6B), confirming that the membrane-proximal residues ${ }^{465}{ }^{2} \mathrm{CRRG}^{469}$ were responsible for the interaction with the AP2 complex. Sim- ilar results were also obtained using GST-ASICla-CT protein pull-down of GFP-tagged AP2 $\mu 2$ heterologously expressed in CHO cells (GST, $5.1 \pm 1.3 \%$; 465-467 A, $30.7 \pm 8.7 \%$; 465-469 A, $5.5 \pm 1.3 \% ; \Delta 465-469,2.5 \pm 0.6 \%$ of AP2 $\mu 2$ binding ability compared with WT ASIC1a-CT) (Fig. 6C,D), confirming the specific requirement of ${ }^{465} \mathrm{LCRRG}^{469}$ for interaction with the AP2 complex. However, as the deletion or alanine substitution of ${ }^{465}{ }^{2 C R R G}{ }^{469}$ also abolished ASICla forward trafficking (D.-S.L. et al., unpublished observations), we were unable to perform surface biotinylation assay to assess the endocytosis rate of these mutants. The membrane-proximal residues ${ }^{465}{ }^{2 C R R G}{ }^{469}$ are unique for ASIC1a/1b among ASIC isoforms in higher vertebrates (Fig. $6 E$ ), indicating that these residues may act as an ASICla/1b specific regulatory motif via recruiting distinctive trafficking machineries.

\section{Inhibition of ASIC1a internalization enhances} acidosis-induced cell death in cortical neurons

Several lines of evidence have demonstrated that ASIC1 a contributes to neuronal death during prolonged acidosis associated with neurodegenerative disorders, including ischemia (Xiong et al., 2004; Gao et al., 2005; Sherwood and Askwith, 2009; Duan et al., 2011). Interestingly, during neurodegeneration, the function of clathrin-dependent endocytic pathway is also reduced by calpain cleavage of several adaptor proteins (Kelly and Ferreira, 2006; Wu et al., 2007; Rudinskiy et al., 2009). Thus, it is reasonable to hypothesize that reduced clathrin-dependent endocytosis of ASICla during neural hyperexcitation or neurodegeneration could exacerbate acidosis-induced neuronal death. To test this possibility, we used dynasore, which effectively inhibits dynamin function and thus blocks the endocytosis of ASICla (Fig. 4E,F), to mimic the dysfunction of clathrin-dependent endocytic pathway and examined how such manipulations affected acidosisinduced neuronal death.

First, the acidosis-induced neuronal death was inspected by morphological examination and labeling dead cells with PI. The PI fluorescence images were merged with the corresponding DIC images (Fig. 7A). To ascertain that the effect was the result of ASIC1a-mediated pathways, cortical neurons prepared from WT and ASIC1a KO mice were used in parallel. In WT neurons treated with the acidic solution $(\mathrm{pH} 6.0,1 \mathrm{~h}$ treatment, $24 \mathrm{~h}$ recovery), the broken membrane morphology resembled a necrotic phenotype (Fig. 7A). With dynasore pretreatment (100 $\mu \mathrm{M}, 30 \mathrm{~min}$ ) followed by the $\mathrm{pH} 6.0$ solution (without dynasore), the cells showed even more severe damage and strong PI signals (Fig. 7A). These changes were not observed in the ASICla KO neurons (Fig. 7A). Because only the WT neurons conferred significant cellular damage when treated with dynasore and the acidic solution, these results provide a strong support that dynamin-mediated endocytosis of ASICla channels is protective to neurons against cellular damages induced by acidosis.

The viability of cells was further quantified by the CTB assay. In WT cortical neurons, acidosis alone caused significant cellular damage ( $\mathrm{pH} 6.0$ treatment reduced viability $55.2 \pm 1.6 \%$ compared with pH 7.4 control; Fig. $7 B$, left). With the pretreatment of dynasore, the effect of acidosis on WT neurons was further enhanced, causing an additional $21.7 \pm 1.3 \%$ reduction of viability compared with acidosis alone (Fig. $7 B$, left). In contrast, acidosis and dynasore treatment failed to induce significant neuronal death in ASICla KO neurons, suggesting that both acidosisinduced neuronal death and its exacerbation by endocytosis blockage were ASIC1a dependent (Fig. $7 B$, right). Consistent with this conclusion, dynole $34-2$ (10 $\mu \mathrm{M}, 30 \mathrm{~min}$ pretreatment), 
A

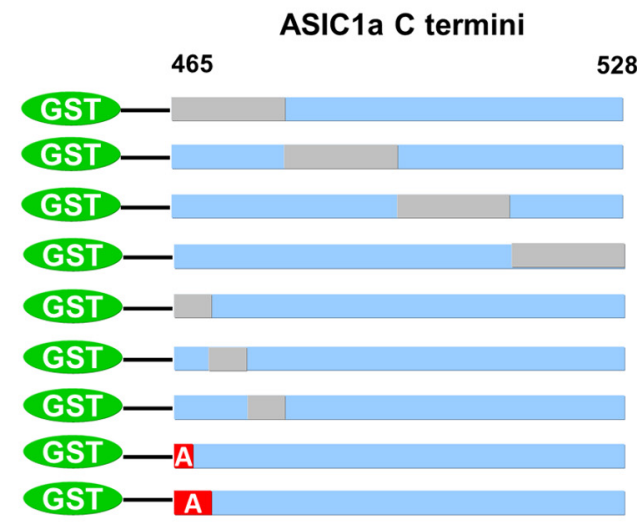

528

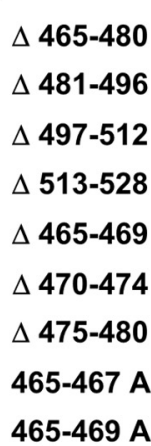

\begin{tabular}{|c|}
$\begin{array}{c}\text { AP2 complex } \\
\text { binding ability }\end{array}$ \\
\hline- \\
+ \\
+ \\
+ \\
- \\
+ \\
+ \\
\pm \\
- \\
\hline
\end{tabular}

B GST-ASIC1a-CT

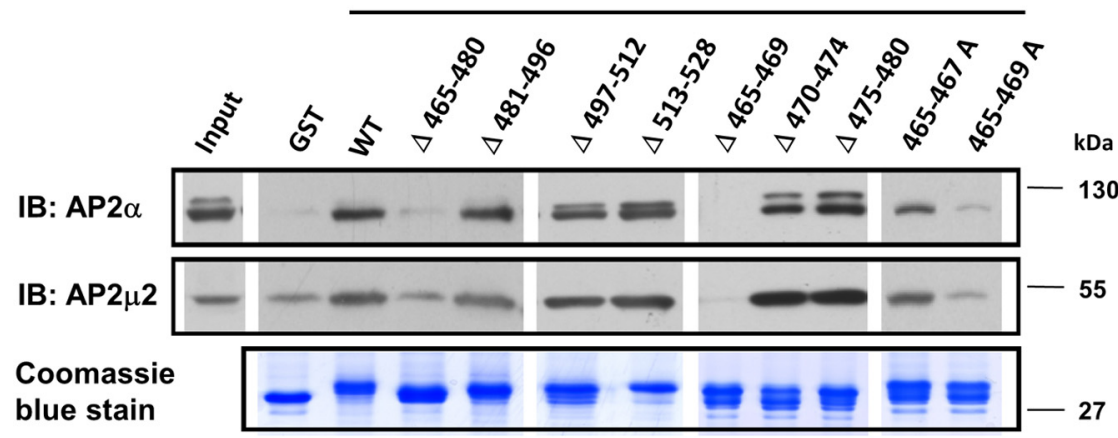

E

\begin{tabular}{|c|c|}
\hline C1a & YEV IKHKKILRRGKCOK̈ \\
\hline mASIC1a & YEVIKI \\
\hline rASIC1a & \\
\hline hASIC1b & \\
\hline mASIC1b & \\
\hline rASIC1b & \\
\hline CASIC1 & YEVIKHRLCRRG \\
\hline SASIC1a & YEVLKHKLCGII \\
\hline sASIC1b & YEVLKHH \\
\hline fASIC 1.1 & YEVLKYKLCRCV \\
\hline fASIC 1.2 & YEVEKDKVLGYEM \\
\hline ZASIC 1.1 & YEVIKEKLCRC \\
\hline ZASIC 1.2 & YEVMKY \\
\hline ZASIC1.3 & YEVLKDKILGS \\
\hline hASIC2a & YELIKEKLLDL. \\
\hline mASIC2a & YELIKEKLLDL \\
\hline rASIC2a & YELIKEKLLDL \\
\hline hASIC2b & YELIK------ \\
\hline mASIC2b & YELIKEKLLDI \\
\hline rASIC2b & YELIKE \\
\hline fASIC2 & YEVT \\
\hline zASIC2 & YEVVKE \\
\hline hASIC3 & CEVERDKVLGYEWI \\
\hline mASIC3 & CEVFQDRVLGYEWN \\
\hline rASIC3 & $\mathrm{CEVH}$ \\
\hline hASCI4 & YEVS \\
\hline rASIC4 & RLKRVWRR \\
\hline zASIC4.1 & YEV \\
\hline ZASIC4.2 & YEVt \\
\hline onsensus & \\
\hline
\end{tabular}

C

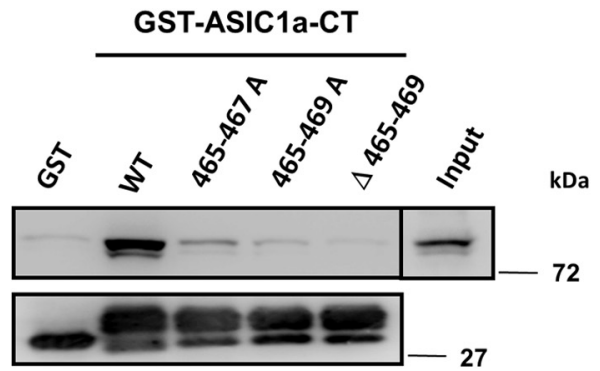

D

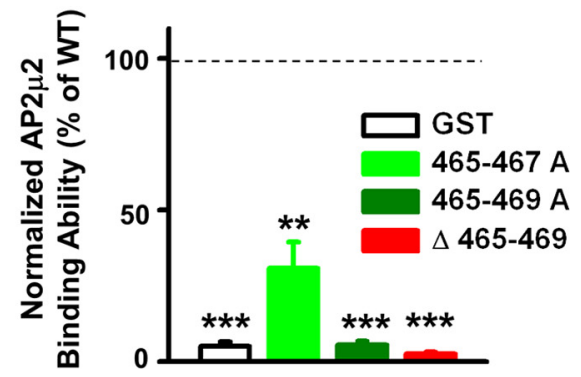

Figure 6. The membrane-proximal residues of ASIC1a C terminus are critical for interaction with the endocytic complex. $A$, Left, Diagrams of various $C$-terminal deletion or mutation constructs fused with GST tag. Deleted regions are shown in gray. Right, Summary of binding results from $\boldsymbol{B} .+, \pm$, and - indicate strong, medium, and weak binding, respectively. $\boldsymbol{B}$, Binding of AP2 complex with GST-fused deletion or mutation constructs of ASIC1a C terminus (CT). GST pull-down experiments were performed using GST-fusion proteins indicated and mouse cerebral cortex extracts, and immunoblotted for AP2 $\alpha$ (top) and AP $2 \mu 2$ (middle). GST fusion proteins were shown by Coomassie blue staining (bottom). Results are representative of three independent experiments. C, Similar GST pull-down assay as in $B$, but lysates from CHO cells expressing GFP-AP2 $\mu 2$ were used. Shown are GFP-AP2 $\mu 2$ (top) pulled down by the purified GST-fusion proteins and detected by IB using anti-GFP antibody. Comparable amounts of GST proteins (bottom) in cell lysates were detected by anti-GST antibody. D, Summary data for intensities of GFP-AP2 $\mu 2$ bands normalized to that pulled down by WT ASIC1a-CT (hyphenated line) in C. Data represent mean \pm SEM; $n=5 .{ }^{* *} p<0.01$ (ANOVA). ${ }^{* * *} p<0.001$ (ANOVA). E, Sequence alignment of different ASIC isoforms at the ASICC termini and adjacent residues indicating that the ${ }^{465} \mathrm{LCRRG}{ }^{469}$ motif is present only in ASIC1a/1b of birds and mammals but not that of lower vertebrates or in other ASIC subunits. $c, \mathrm{f}, \mathrm{h}$, $\mathrm{m}, \mathrm{r}, \mathrm{s}$, and z indicate chicken, toadfish, human, mouse, rat, shark, and zebrafish, respectively.

a novel and potent dynamin inhibitor that targets dynamin at the GTPase allosteric domain (Hill et al., 2009), showed similar effects on neuronal death as dynasore in WT, but not ASIC1a KO neurons (data not shown). The negative control structural analog of dynole 34-2, dynole 31-2, did not enhance acid-induced neuronal death, even in WT cells (data not shown).

Although the involvement of ASIC1a in acidosis-induced neuronal death has been well established, the underlying mechanism(s) for the ASICla-mediated cell death remains controversial. Calcium influx via homomeric ASIC1a channels was originally considered as the primary reason (Xiong et al., 2004; Yermolaieva et al., 2004); however, the fast desensitization of the ASICla channel, which occurs within a few seconds during persistent acidosis (Duan et al., 2011), is inconsistent with the observation that severity of neuronal damage is correlated with the duration of acid exposure. In addition, ASICs allow much less calcium entry than typical $\mathrm{Ca}^{2+}$ channels, such as voltage-gated $\mathrm{Ca}^{2+}$ channels (Samways et al., 2009). Because blocking ASIC1a endocytosis with dynasore enhanced acidosis-induced neuronal death, we asked whether this effect was dependent of the acid-evoked ASIC1a currents. The tarantula toxin psalmotoxin 1 (PcTX1) is a selective inhibitor of ASIC1a homomeric (Escoubas et al., 2000) and ASIC1a/2b heteromeric channels (Sherwood et al., 2011). We used a saturating concentration of PcTX1 $(0.2 \mu \mathrm{M})$ to ensure a complete block of the ASIC1a current (Sherwood et al., 2011). In WT cortical neurons, PcTX1 $(0.2 \mu \mathrm{M}, 30$-min pretreatment and $1 \mathrm{~h}$ during $\mathrm{pH}$ 6.0) largely rescued the acidosis-induced neuronal death (viability with PcTX1-pH 6.0 was $86.4 \pm 1.6 \%$ of that 
A

Veh-pH 7.4

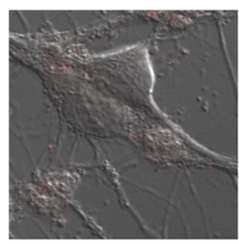

KO

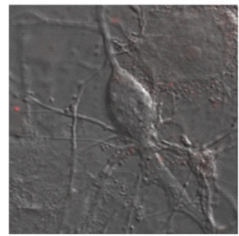

Veh-pH 6.0
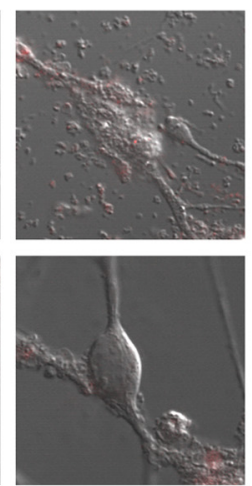

Merged: DIC + P
Dyna-pH 7.4
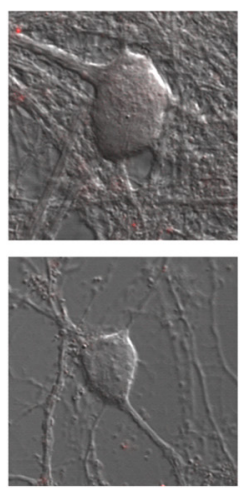

C
B

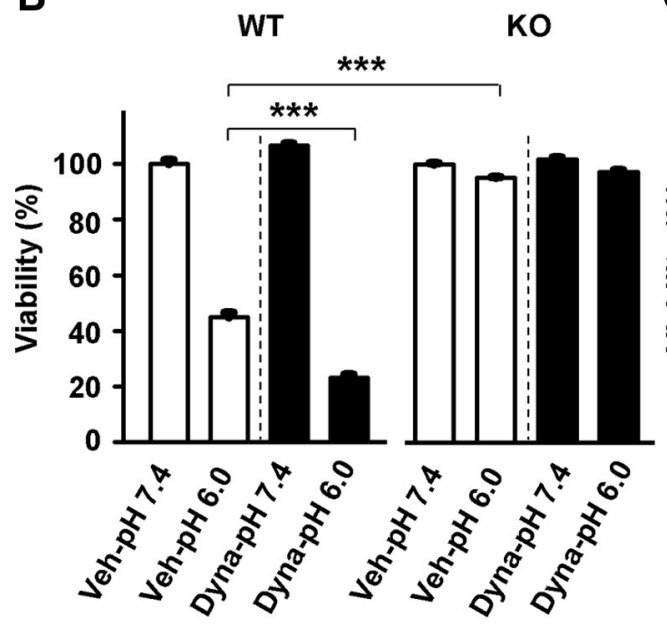

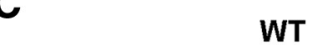

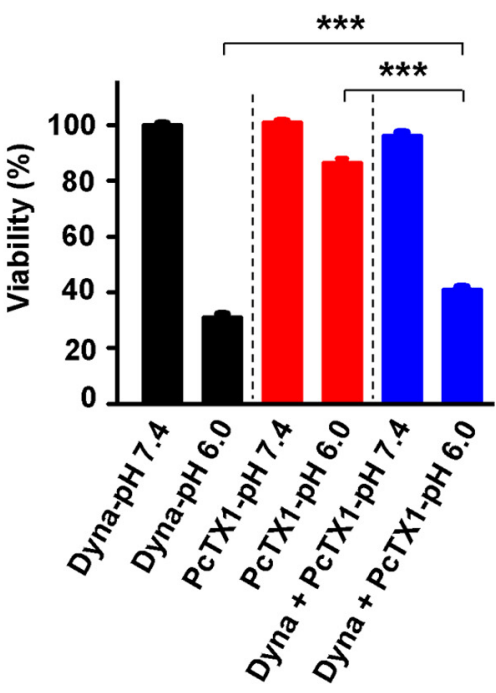

Figure 7. Inhibition of ASIC1a internalization enhances acidosis-induced death of mouse cortical neurons. $A$, Pretreatment with dynasore (Dyna, $100 \mu \mathrm{m}, 30 \mathrm{~min}$ ) enhanced neuronal death induced by acidosis ( $\mathrm{pH} 6.0$ for 1 and $24 \mathrm{~h}$ recovery, dynasore not present during the $\mathrm{pH} 6.0$ treatment) in WT but not ASIC1a KO cortical neurons. Representative images of DIC and PI staining (red) for $n \geq 20$ cells for each condition. Scale bar, $10 \mu \mathrm{m}$. B, Summary data of cell viability under conditions shown in $\boldsymbol{A}$ but measured using the CTB assay. Data represent mean \pm SEM normalized to results obtained in Veh at pH 7.4. ${ }^{* *} p<0.001$, from three different cultures for WT and ASIC1 a KO cortical neurons with four repeats each time (unpaired $t$ test). C, Differential effects of PCTX1 $(0.2 \mu \mathrm{M}, 30 \mathrm{~min}$ before and during acidosis) on acid-induced neuronal death without or with pretreatment of dynasore as in $A$ and B. WT mouse cortical neurons were used. Data represent mean $\pm S E M$ of CTB assay results normalized to that of dynasore-treated neurons at $\mathrm{pH}$ 7.4. ${ }^{* * *} p<0.001$, from three independent cultures for WT mouse cortical neurons with four repeats each time (unpaired $t$ test).

PcTX1-pH 7.4), but with the pretreatment by dynasore, it only showed a slight rescue of acid-induced neuronal death (Dyna + PcTX1-pH 6.0 increased $9.8 \pm 1.0 \%$ viability compared with Dyna-pH 6.0 alone but reduced $45.6 \pm 1.2 \%$ viability compared with PcTX1-pH 6.0) (Fig. 7C). These data indicate that a channel activity-independent mechanism may also be involved in the ASICla-dependent acidosis-induced neuronal death exacerbated by dynasore. Together, our results indicate the importance of endocytic pathways in acidosisinduced neuronal death and that this regulation is mainly mediated via membrane retention of ASIC1a proteins.

\section{Discussion}

Regulation of ASIC channel activity by membrane trafficking has emerged as one of the main mechanisms that affect ASIC function under normal and pathophysiological conditions
(Chai et al., 2010; Duan et al., 2012). However, how endocytosis of ASICs is regulated and its physiological and pathophysiological relevance remained largely unknown. In the present work, we show that the surface density of ASICla is regulated by endocytosis through the dynamin-dependent clathrin-mediated pathway. Membrane-proximal residues ${ }^{465}{ }^{2 C R R G}{ }^{469}$ at the C terminus of ASIC1a appeared to be important for interacting with the endocytic protein complex. In particular, we found that inhibition of ASIC1a internalization in cultured neurons exacerbated acidosis-induced neuronal death (Fig. 8).

\section{Critical role of membrane-proximal residues ${ }^{465} \mathrm{LCRRG}^{469}$ in the regulation of ASIC1 a trafficking}

Numerous studies have identified protein sequence motifs in cytoplasmic regions of many surface receptors, such as YXXØ, [DE]XXXL[LIM], [FY]XNPX[YF] etc., for cargo selection during endocytosis (Traub, 2009). However, although the membraneproximal YERL residues at the ASICla N terminus confers the YXXØ sorting motif, our GST pull-down results showed a much weaker interaction of the ASICla N terminus with the adaptor proteins than the ASICla C terminus (Fig. 5). The ${ }^{465}$ LCRRG $^{469}$ residues are located very close to the transmembrane domain 2 and are conserved among ASIC1 isoforms in high vertebrates (birds and mammals) (Fig. 6E). However, this sequence does not resemble any of the conventional endocytic sorting motifs (Traub, 2009), raising the possibility that it may bind to unknown adaptor proteins, which further interact with the AP2 complex. Indeed, several regulatory proteins of ASICla bind to its $\mathrm{C}$ terminus (Wemmie et al., 2006; Lingueglia, 2007). Another interpretation based on the GST pull-down results is that the ${ }^{465} \mathrm{LCRRG}^{469}$ residues are important for maintaining the C-terminal tertiary structure, which is critical for interaction with the AP2 complex. The positively charged motif may interact with lipids within plasma membrane, such as $\mathrm{PI}(4,5) \mathrm{P}_{2}$ and $\mathrm{PI}(3,4,5) \mathrm{P}_{3}$, to further stabilize the receptors (von Heijne, 1992; Heo et al., 2006). Supporting the importance of protein tertiary structure in channel trafficking, we recently identified that a highly conserved salt-bridge $\left({ }^{107} \mathrm{D} \ldots \mathrm{R}^{153}\right.$ of rat ASIC3, ${ }^{107} \mathrm{D} \ldots \mathrm{R}^{160}$ of human ASIC1a) stabilizing a rigid signal patch at the extracellular loop is critical for surface expression of ASICs (Yang et al., 2012). Furthermore, Golgi exit of Kir2.1 is dictated by residues that are embedded within the confluence of two separate domains, rather than a short linear sequence (Ma et al., 2011). Thus, it is reasonable to assume that the membrane-proximal residues ${ }^{465} \mathrm{LCRRG}^{469}$ are critical in maintaining the tertiary structure of the ASIC1a C terminus, which in turn allows the binding of reg- 
ulatory proteins. Future work should focus on identification of the binding partners for this critical motif of ASICla.

\section{Abnormal endocytosis of ASIC1a during neurodegeneration contributes to neuronal death}

Many ion channels and membrane proteins, such as AMPA receptors, kainate receptors, and N-cadherin, undergo both constitutive and regulated endocytosis, which act cooperatively to achieve homeostasis and/or plasticity in response to different environmental changes (Beattie et al., 2000; Ehlers, 2000; Martin and Henley, 2004; Green et al., 2007; Tai et al., 2007; Fang et al., 2009). Studies have also shown that impairments of endocytic pathways contributed to pathophysiology of neurodegeneration in progressive disorders, such as Alzheimer's disease, Huntington disease, and primary lateral sclerosis (Nixon, 2005), and acute disorders, such as ischemia, seizures, and neuroexcitotoxicity (Kelly and Ferreira, 2006; Wu et al., 2007; Rudinskiy et al., 2009; Troulinaki and Tavernarakis, 2012). In addition to the endosome and lysosome abnormalities (Nixon, 2005), the function of the upstream endocytic pathway was severely attenuated by calpain-dependent cleavage of the core endocytic components, such as AP2 $\alpha$, AP2 $\beta 2$, dynamin 1, and amphiphysin I (Kelly and Ferreira, 2006; Wu et al., 2007; Rudinskiy et al., 2009), leading to membrane retention of receptors that normally internalize via the clathrindependent pathway.

The present work not only supports the essential role of ASICla in acidosis-induced neuronal death but also reveals an additional role of ASIC1a endocytosis in this process (Fig. 7). It was interesting that, although inhibiting the channel function of ASIC1a with PcTX1 largely attenuated the acid-induced death of cultured mouse cortical neurons under normal conditions with intact endocytosis, it had very little impact on the cell death when endocytosis was blocked by the pretreatment with dynasore (Fig. 7C). Arguably, dynasore does not specifically act on endocytosis of ASIC1a and may exert its effects on cell death through other targets. However, the findings that the same treatment with dynasore failed to induce significant death of both WT and ASICla KO neurons at the neutral pH and ASICla KO neurons at acidic pH (Fig. $7 B$ ) suggest that both the expression of ASICla and extracellular acidification are essential for the dynasore treatment-evoked neuronal death under our experimental conditions. Our data thus demonstrate an ASIC1amediated neuronal death pathway that requires the proton sensor function but not the channel conductance and is regulated by dynamin-mediated endocytosis. Inhibiting ASIC1a endocytosis by dynasore enhanced this pathway and this enhancement was more evident when ASIC1a channel function was blocked by PcTX1. The channel conductance-independent role of ASIC1a in neuronal death would help explain how ASIC1a contributes to acidosis-induced death, the severity of which is correlated with the duration of acid treatment, whereas acid-induced currents through ASIC1a typically subside in a few seconds (Duan et al., 2011). Interestingly, we did not detect an obvious change in the

\section{Acidosis}

Membrane retention $\Longrightarrow$ Enhanced neuronal death

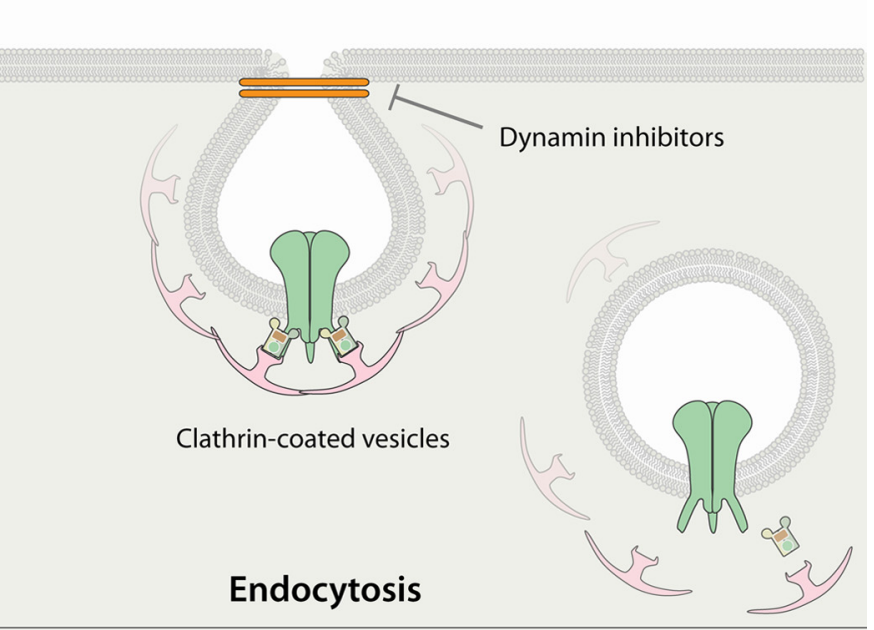

us

EAKRSSADKGVALSLDDVKRHNPCESLRGHPAGMTYAANILPHHPARGTFEDFTC

PDZ motif

rate of endocytosis of ASIC1a in response to extracellular acidification in mouse cortical neurons (data not shown), suggesting that the protective role of endocytosis is neither enhanced nor reduced during acidosis. It would be interesting in future studies to examine what kind of death signal(s) is activated through extracellular proton binding to ASIC1a and how endocytosis modulates the generation and/or action of such a signal.

Importantly, ASICla has been implicated in pathogenesis of ischemia, multiple sclerosis, Huntington's disease, and Parkinson's disease (Xiong et al., 2004; Gao et al., 2005; Friese et al., 2007; Arias et al., 2008; Wong et al., 2008; Xiong et al., 2008; Duan et al., 2011), and tissue acidosis is tightly associated with many neurodegenerative disorders, such as ischemia, epileptic seizure, and brain trauma (Xiong et al., 2008; Wang and Xu, 2011). Therefore, the acid-induced ASIC1a activities, being conductance dependent or not, play a central role in the pathophysiology of neurodegenerative diseases. Given the current finding that endocytosis of ASICla is regulated by clathrin- and dynamindependent endocytosis (Figs. 3 and 4), which contributes critically to acidosis-induced neuronal death (Fig. 7), it is reasonable to assume that altered endocytosis of ASIC1a during the process of neurodegeneration may play a pivotal role in exacerbating ASICla-mediated neuronal death. This will be of particular relevance to the treatment and prevention of neurodegeneration in diseases mentioned above.

In conclusion, our data indicate that ASICla undergoes constitutive dynamin-dependent endocytosis, which results in a downregulation of ASICla surface expression. Although this endocytosis of ASIC1a is also largely clathrin-dependent, there is a clathrinindependent component of endocytosis that requires further investigation. We have identified a novel noncanonical sorting signal (the C-terminal residues ${ }^{465} \mathrm{LCRRG}^{469}$ ) for association of ASICla with 
the AP2 endocytic complex. We also show that blockade of ASIC1a endocytosis exacerbates acidosis-induced neuronal death (Fig. 8), and this likely occurs through a conductance-independent function of ASICla. We propose that ${ }^{465}{ }^{2 C R R G}{ }^{469}$ residues may act as an important regulatory motif by affecting either the tertiary structure of ASICla C terminus or binding to specific trafficking proteins. These results thus reveal a novel trafficking mechanism of ASIC1a in the brain and implicate the endocytic pathway of ASICs as a novel therapeutic target to alleviate neuronal damage during the progression of neurodegeneration.

\section{References}

Arias RL, Sung ML, Vasylyev D, Zhang MY, Albinson K, Kubek K, Kagan N, Beyer C, Lin Q, Dwyer JM, Zaleska MM, Bowlby MR, Dunlop J, Monaghan M (2008) Amiloride is neuroprotective in an MPTP model of Parkinson's disease. Neurobiol Dis 31:334-341. CrossRef Medline

Banbury DN, Oakley JD, Sessions RB, Banting G (2003) Tyrphostin A23 inhibits internalization of the transferrin receptor by perturbing the interaction between tyrosine motifs and the medium chain subunit of the AP-2 adaptor complex. J Biol Chem 278:12022-12028. CrossRef Medline

Beattie EC, Carroll RC, Yu X, Morishita W, Yasuda H, von Zastrow M, Malenka RC (2000) Regulation of AMPA receptor endocytosis by a signaling mechanism shared with LTD. Nat Neurosci 3:1291-1300. CrossRef Medline

Chai S, Li M, Branigan D, Xiong ZG, Simon RP (2010) Activation of acidsensing ion channel 1a (ASICla) by surface trafficking. J Biol Chem 285: 13002-13011. CrossRef Medline

Chen X, Gründer S (2007) Permeating protons contribute to tachyphylaxis of the acid-sensing ion channel (ASIC) 1a. J Physiol 579:657-670. CrossRef Medline

Damke H, Baba T, Warnock DE, Schmid SL (1994) Induction of mutant dynamin specifically blocks endocytic coated vesicle formation. J Cell Biol 127:915-934. CrossRef Medline

Daukas G, Zigmond SH (1985) Inhibition of receptor-mediated but not fluid-phase endocytosis in polymorphonuclear leukocytes. J Cell Biol 101: 1673-1679. CrossRef Medline

Duan B, Wu LJ, Yu YQ, Ding Y, Jing L, Xu L, Chen J, Xu TL (2007) Upregulation of acid-sensing ion channel ASIC1a in spinal dorsal horn neurons contributes to inflammatory pain hypersensitivity. J Neurosci 27:11139-11148. CrossRef Medline

Duan B, Wang YZ, Yang T, Chu XP, Yu Y, Huang Y, Cao H, Hansen J, Simon RP, Zhu MX, Xiong ZG, Xu TL (2011) Extracellular spermine exacerbates ischemic neuronal injury through sensitization of ASICla channels to extracellular acidosis. J Neurosci 31:2101-2112. CrossRef Medline

Duan B, Liu DS, Huang Y, Zeng WZ, Wang X, Yu H, Zhu MX, Chen ZY, Xu TL (2012) PI3-kinase/Akt pathway-regulated membrane insertion of acid-sensing ion channel 1a underlies BDNF-induced pain hypersensitivity. J Neurosci 32:6351-6363. CrossRef Medline

Ehlers MD (2000) Reinsertion or degradation of AMPA receptors determined by activity-dependent endocytic sorting. Neuron 28:511-525. CrossRef Medline

Escoubas P, De Weille JR, Lecoq A, Diochot S, Waldmann R, Champigny G, Moinier D, Ménez A, Lazdunski M (2000) Isolation of a tarantula toxin specific for a class of proton-gated $\mathrm{Na}+$ channels. J Biol Chem 275: 25116-25121. CrossRef Medline

Fang L, Garuti R, Kim BY, Wade JB, Welling PA (2009) The ARH adaptor protein regulates endocytosis of the ROMK potassium secretory channel in mouse kidney. J Clin Invest 119:3278-3289. CrossRef Medline

Ferguson SM, Brasnjo G, Hayashi M, Wölfel M, Collesi C, Giovedi S, Raimondi A, Gong LW, Ariel P, Paradise S, O'Toole E, Flavell R, Cremona O, Miesenböck G, Ryan TA, De Camilli P (2007) A selective activitydependent requirement for dynamin 1 in synaptic vesicle endocytosis. Science 316:570-574. CrossRef Medline

Friese MA, Craner MJ, Etzensperger R, Vergo S, Wemmie JA, Welsh MJ, Vincent A, Fugger L (2007) Acid-sensing ion channel-1 contributes to axonal degeneration in autoimmune inflammation of the central nervous system. Nat Med 13:1483-1489. CrossRef Medline

Gao J, Duan B, Wang DG, Deng XH, Zhang GY, Xu L, Xu TL (2005) Coupling between NMDA receptor and acid-sensing ion channel contributes to ischemic neuronal death. Neuron 48:635-646. CrossRef Medline

Green EM, Barrett CF, Bultynck G, Shamah SM, Dolmetsch RE (2007) The tumor suppressor eIF3e mediates calcium-dependent internalization of the L-type calcium channel CaV1.2. Neuron 55:615-632. CrossRef Medline

Gründer S, Chen X (2010) Structure, function, and pharmacology of acidsensing ion channels (ASICs): focus on ASICla. Int J Physiol Pathophysiol Pharmacol 2:73-94. Medline

Hallett PJ, Collins TL, Standaert DG, Dunah AW (2008) Biochemical fractionation of brain tissue for studies of receptor distribution and trafficking. Curr Protoc Neurosci Chapter 1:Unit 1.16. CrossRef Medline

Henry PC, Kanelis V, O’Brien MC, Kim B, Gautschi I, Forman-Kay J, Schild L, Rotin D (2003) Affinity and specificity of interactions between Nedd4 isoforms and the epithelial Na + channel. J Biol Chem 278:20019-20028. CrossRef Medline

Heo WD, Inoue T, Park WS, Kim ML, Park BO, Wandless TJ, Meyer T (2006) $\mathrm{PI}(3,4,5) \mathrm{P} 3$ and $\mathrm{PI}(4,5) \mathrm{P} 2$ lipids target proteins with polybasic clusters to the plasma membrane. Science 314:1458-1461. CrossRef Medline

Heuser JE, Anderson RG (1989) Hypertonic media inhibit receptormediated endocytosis by blocking clathrin-coated pit formation. J Cell Biol 108:389-400. CrossRef Medline

Hill TA, Gordon CP, McGeachie AB, Venn-Brown B, Odell LR, Chau N, Quan A, Mariana A, Sakoff JA, Chircop M, Robinson PJ, McCluskey A (2009) Inhibition of dynamin mediated endocytosis by the dynoles: synthesis and functional activity of a family of indoles. J Med Chem 52:37623773. CrossRef Medline

Hruska-Hageman AM, Wemmie JA, Price MP, Welsh MJ (2002) Interaction of the synaptic protein PICK1 (protein interacting with C kinase 1) with the non-voltage gated sodium channels BNC1 (brain $\mathrm{Na}+$ channel 1) and ASIC (acid-sensing ion channel). Biochem J 361:443-450. CrossRef Medline

Kellenberger S, Schild L (2002) Epithelial sodium channel/degenerin family of ion channels: a variety of functions for a shared structure. Physiol Rev 82:735-767. CrossRef Medline

Kelly BL, Ferreira A (2006) $\beta$-Amyloid-induced dynamin 1 degradation is mediated by N-methyl-D-aspartate receptors in hippocampal neurons. J Biol Chem 281:28079-28089. CrossRef Medline

Knight KK, Olson DR, Zhou R, Snyder PM (2006) Liddle's syndrome mutations increase $\mathrm{Na}+$ transport through dual effects on epithelial $\mathrm{Na}+$ channel surface expression and proteolytic cleavage. Proc Natl Acad Sci U S A 103:2805-2808. CrossRef Medline

Lingueglia E (2007) Acid-sensing ion channels in sensory perception. J Biol Chem 282:17325-17329. CrossRef Medline

Ma D, Taneja TK, Hagen BM, Kim BY, Ortega B, Lederer WJ, Welling PA (2011) Golgi export of the Kir2.1 channel is driven by a trafficking signal located within its tertiary structure. Cell 145:1102-1115. CrossRef Medline

Macia E, Ehrlich M, Massol R, Boucrot E, Brunner C, Kirchhausen T (2006) Dynasore, a cell-permeable inhibitor of dynamin. Dev Cell 10:839-850. CrossRef Medline

Mankouri J, Taneja TK, Smith AJ, Ponnambalam S, Sivaprasadarao A (2006) Kir6.2 mutations causing neonatal diabetes prevent endocytosis of ATPsensitive potassium channels. EMBO J 25:4142-4151. CrossRef Medline

Martin S, Henley JM (2004) Activity-dependent endocytic sorting of kainate receptors to recycling or degradation pathways. EMBO J 23: 4749-4759. CrossRef Medline

McMahon HT, Boucrot E (2011) Molecular mechanism and physiological functions of clathrin-mediated endocytosis. Nat Rev Mol Cell Biol 12: 517-533. CrossRef Medline

Nixon RA (2005) Endosome function and dysfunction in Alzheimer's disease and other neurodegenerative diseases. Neurobiol Aging 26:373-382. CrossRef Medline

Piwon N, Günther W, Schwake M, Bösl MR, Jentsch TJ (2000) ClC-5 Cl-channel disruption impairs endocytosis in a mouse model for Dent's disease. Nature 408:369-373. CrossRef Medline

Praefcke GJ, McMahon HT (2004) The dynamin superfamily: universal membrane tubulation and fission molecules? Nat Rev Mol Cell Biol 5:133-147. CrossRef Medline

Rudinskiy N, Grishchuk Y, Vaslin A, Puyal J, Delacourte A, Hirling H, Clarke PG, Luthi-Carter R (2009) Calpain hydrolysis of $\alpha$ - and $\beta 2$-adaptins decreases clathrin-dependent endocytosis and may promote neurodegeneration. J Biol Chem 284:12447-12458. CrossRef Medline

Samways DS, Harkins AB, Egan TM (2009) Native and recombinant 
ASIC1a receptors conduct negligible $\mathrm{Ca}^{2+}$ entry. Cell Calcium 45: 319-325. CrossRef Medline

Schild L, Lu Y, Gautschi I, Schneeberger E, Lifton RP, Rossier BC (1996) Identification of a PY motif in the epithelial $\mathrm{Na}$ channel subunits as a target sequence for mutations causing channel activation found in Liddle syndrome. EMBO J 15:2381-2387. Medline

Sherwood TW, Askwith CC (2009) Dynorphin opioid peptides enhance acid-sensing ion channel la activity and acidosis-induced neuronal death. J Neurosci 29:14371-14380. CrossRef Medline

Sherwood TW, Lee KG, Gormley MG, Askwith CC (2011) Heteromeric acid-sensing ion channels (ASICs) composed of ASIC2b and ASIC1a display novel channel properties and contribute to acidosis-induced neuronal death. J Neurosci 31:9723-9734. CrossRef Medline

Shimkets RA, Warnock DG, Bositis CM, Nelson-Williams C, Hansson JH, Schambelan M, Gill JR Jr, Ulick S, Milora RV, Findling JW, et al. (1994) Liddle's syndrome: heritable human hypertension caused by mutations in the $\beta$ subunit of the epithelial sodium channel. Cell 79:407-414. CrossRef Medline

Snyder PM, Price MP, McDonald FJ, Adams CM, Volk KA, Zeiher BG, Stokes JB, Welsh MJ (1995) Mechanism by which Liddle's syndrome mutations increase activity of a human epithelial $\mathrm{Na}+$ channel. Cell 83:969978. CrossRef Medline

Sorkin A, von Zastrow M (2009) Endocytosis and signalling: intertwining molecular networks. Nat Rev Mol Cell Biol 10:609-622. CrossRef Medline

Tai CY, Mysore SP, Chiu C, Schuman EM (2007) Activity-regulated $\mathrm{N}$-cadherin endocytosis. Neuron 54:771-785. CrossRef Medline

Traub LM (2009) Tickets to ride: selecting cargo for clathrin-regulated internalization. Nat Rev Mol Cell Biol 10:583-596. CrossRef Medline

Troulinaki K, Tavernarakis N (2012) Endocytosis and intracellular trafficking contribute to necrotic neurodegeneration in C. elegans. EMBO J 31: 654-666. CrossRef Medline

van der Bliek AM, Redelmeier TE, Damke H, Tisdale EJ, Meyerowitz EM, Schmid SL (1993) Mutations in human dynamin block an intermediate stage in coated vesicle formation. J Cell Biol 122:553-563. CrossRef Medline

von Heijne G (1992) Membrane protein structure prediction: hydropho- bicity analysis and the positive-inside rule. J Mol Biol 225:487-494. CrossRef Medline

Wang H, Traub LM, Weixel KM, Hawryluk MJ, Shah N, Edinger RS, Perry CJ, Kester L, Butterworth MB, Peters KW, Kleyman TR, Frizzell RA, Johnson JP (2006) Clathrin-mediated endocytosis of the epithelial sodium channel: role of epsin. J Biol Chem 281:14129-14135. CrossRef Medline

Wang YZ, Xu TL (2011) Acidosis, acid-sensing ion channels, and neuronal cell death. Mol Neurobiol 44:350-358. CrossRef Medline

Wemmie JA, Price MP, Welsh MJ (2006) Acid-sensing ion channels: advances, questions and therapeutic opportunities. Trends Neurosci 29: 578-586. CrossRef Medline

Wong HK, Bauer PO, Kurosawa M, Goswami A, Washizu C, Machida Y, Tosaki A, Yamada M, Knöpfel T, Nakamura T, Nukina N (2008) Blocking acid-sensing ion channel 1 alleviates Huntington's disease pathology via an ubiquitin-proteasome system-dependent mechanism. Hum Mol Genet 17:3223-3235. CrossRef Medline

Wu Y, Liang S, Oda Y, Ohmori I, Nishiki T, Takei K, Matsui H, Tomizawa K (2007) Truncations of amphiphysin I by calpain inhibit vesicle endocytosis during neural hyperexcitation. EMBO J 26:2981-2990. CrossRef Medline

Xiong ZG, Zhu XM, Chu XP, Minami M, Hey J, Wei WL, MacDonald JF, Wemmie JA, Price MP, Welsh MJ, Simon RP (2004) Neuroprotection in ischemia: blocking calcium-permeable acid-sensing ion channels. Cell 118:687-698. CrossRef Medline

Xiong ZG, Pignataro G, Li M, Chang SY, Simon RP (2008) Acid-sensing ion channels (ASICs) as pharmacological targets for neurodegenerative diseases. Curr Opin Pharmacol 8:25-32. CrossRef Medline

Xu TL, Duan B (2009) Calcium-permeable acid-sensing ion channel in nociceptive plasticity: a new target for pain control. Prog Neurobiol 87:171180. CrossRef Medline

Yang Y, Yu Y, Cheng J, Liu Y, Liu DS, Wang J, Zhu MX, Wang R, Xu TL (2012) Highly conserved salt bridge stabilizes rigid signal patch at extracellular loop critical for surface expression of acid-sensing ion channels. J Biol Chem 287:14443-14455. CrossRef Medline

Yermolaieva O, Leonard AS, Schnizler MK, Abboud FM, Welsh MJ (2004) Extracellular acidosis increases neuronal cell calcium by activating acidsensing ion channel 1a. Proc Natl Acad Sci U S A 101:6752-6757. CrossRef Medline 